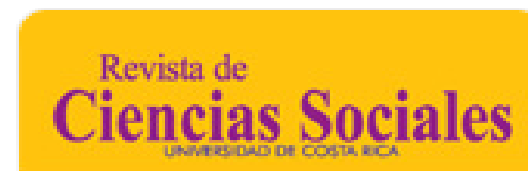

Solís Avendaño, Manuel Antonio

DOS HECHOS INSÓLITOS Y ALGO DE PERSPECTIVA

Revista de Ciencias Sociales (Cr), vol. II, núm. 144, 2014, pp. 29-66

Universidad de Costa Rica

San José, Costa Rica

Disponible en: http://www.redalyc.org/articulo.oa?id=15333872003

- Cómo citar el artículo

- Número completo

- Más información del artículo

- Página de la revista en redalyc.org

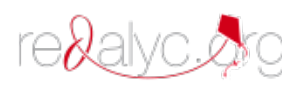

Sistema de Información Científica

Red de Revistas Científicas de América Latina, el Caribe, España y Portugal

Proyecto académico sin fines de lucro, desarrollado bajo la iniciativa de acceso abierto 


\title{
DOS HECHOS INSÓLITOS Y ALGO DE PERSPECTIVA
}

\section{TWO UNBELIEVABLE FACTS AND SOME PERSPECTIVE}

\author{
Manuel Antonio Solís Avendaño*
}

\author{
RESUMEN
}

Este artículo hace referencia a los acontecimientos que rodearon primeramente, la no reelección del magistrado constitucional Fernando Cruz Castro y posteriormente, su reelección, en noviembre de 2012. El suceso, tratado en su momento como un hecho insólito y sin precedentes, es interpretado en este artículo como una expresión conspicua de la institucionalidad y del sistema político que han tomando forma en los últimos 30 años, en el curso del llamado proceso de apertura, cuyo norte es el mercado y al mismo tiempo, una ventana adicional para observar la erosión del sistema de división de poderes establecido en la Constitución de 1949.

PALABRAS CLAVE: COSTA RICA* PODER EJECUTIVO * PODER JUDICIAL * PODER LEGISLATIVO $*$ SALA CONSTITUCIONAL * ELECCIONES * DEMOCRACIA * GOBERNABILIDAD * PARTIDOS POLÍTICOS

\section{ABSTRACT}

This article deals with the events surrounding both, the non re-election and the reelection of the constitutional judge Fernando Cruz Castro, on November 2012. The event was treated as an unprecedented and unique situation. However, in this article it is seen as a conspicuous expression of our institutional order and our political system, which have been shaped during the last thirty years, throughout the market opening process. At the same time, it can be taken as an additional window through which we can observe the erosion of the separation of powers established in the Constitution of 1949.

KEYWORDS: COSTA RICA * EXECUTIVE POWER * JUDICIAL POWER * LEGISLATIVE POWER $*$ CONSTITUTIONAL TRIBUNAL * ELECTIONS * DEMOCRACY * GOVERNANCE * POLITICAL PARTIES

* Instituto de Investigaciones Sociales de la Universidad de Costa Rica. manuelantonio.solis@gmail.com 


\section{UN PRIMER HECHO INSÓLITO}

El 15 de noviembre del 2012 la Asamblea Legislativa de Costa Rica decidió por 38 votos, la no reelección del magistrado de la Sala Constitucional, Fernando Cruz Castro. Solo doce de los 50 diputados $y$ diputadas presentes se pronunciaron a favor de mantenerlo en el cargo. Minutos antes de la votación, un diputado se refirió a una "información reciente", que él esperaba no fuese correcta, sobre la intención de no ratificar al magistrado Cruz, algo que de ser cierto daría cuenta de un suceso "inédito", "indicador de facturas que estarían siendo cobradas" ese día (Acta de la Sesión Plenaria de la Asamblea Legislativa-ASPAL nro. 99, 2012: 7)1 ${ }^{1}$. La intervención fue sumamente corta y no tuvo eco. Minutos después lo anticipado se hizo realidad y Cruz no era reelecto. No obstante, cinco días más tarde, el 20 de noviembre, el presidente de la Asamblea Legislativa anuló el acto de no reelección del magistrado Cruz, calificándolo de "extemporáneo". De seguido, lo declaraba reelecto "de manera automática" a partir del 19 de octubre anterior, un mes después que la Corte Suprema de Justicia comunicara a la Asamblea el vencimiento del nombramiento, el siguiente 18 de octubre (ASPAL nro. 101, 2012: $5-11)^{2}$. Cuando se votó el pronunciamiento de la presidencia de la Asamblea, el bloque de los 38 votos se había desgranado, pero persistía una columna vertebral compuesta por el Partido Liberación Nacional (PLN).

Los días comprendidos entre el 15 y el 20 de noviembre de 2012, dibujaron un cuadro importante de examinar. La no reelección del magistrado provocó una colisión frontal entre la cúpula del Poder Judicial y un sector mayoritario del Poder Legislativo, respaldado por el Poder Ejecutivo — cuando menos esas fueron las apariencias en el momento.

Para quienes estaban a favor de Cruz, lo acaecido el día 15 ponía el ordenamiento constitucional existente al borde de una crisis de grandes proporciones. Lo suficiente para volver

$1 \quad$ Intervención del diputado Juan Carlos Mendoza García.

2 Pronunciamiento del presidente de la Asamblea Legislativa Víctor Emilio Granados Calvo. a invocar en el Plenario Legislativo y fuera de este, la década de los 40 y el año 1948, símbolo en nuestra historia de la fractura social, el desgarre institucional y la violencia. También para que prendiera con renovada fuerza la sospecha de otro intento, esta vez más directo y atrevido, para orientar las decisiones de la Sala Constitucional y de la Corte a favor de intereses particulares específicos.

La activa intervención del ministro de la Presidencia en la conformación del bloque contrario a la reelección apoyaba esta suposición; la prensa, las actas de la Asamblea Legislativa $y$ los testimonios aportan indicios concluyentes de un intenso trabajo de negociación, persuasión, presión (colindante con el acoso, según una diputada), coordinado desde la Casa Presidencial (ASPAL nro. 102, 2012: 15-16) ${ }^{3}$, una intervención que recuerda la abundante literatura sobre la vulnerabilidad $y$ falta de independencia del Poder Judicial frente al Poder Ejecutivo en América Latina. En este caso, sin embargo, el Ejecutivo no parecía ser el único actor interesado en la no reelección del magistrado Cruz; las denuncias realizadas en el recinto legislativo apuntaron a las empresas farmacéuticas y a sectores vinculados a la producción privada de energía, a los intereses ligados con Industrias Infinito y Crucitas, así como, renombrados políticos interesados en causas que podían llegar (o volver) a la Sala Constitucional. Tal sería la parte más visible de un sistema de redes de intereses cuyas extensiones reales son difíciles de establecer. En un futuro entonces impreciso, la Sala Constitucional debía resolver si admitía una acción de inconstitucionalidad interpuesta por la minera canadiense Industrias Infinito, en noviembre de 2011, con la pretensión de enmendar la decisión del Tribunal Contencioso Administrativo y de la Sala Primera, la cual cancelaba la concesión otorgada, debido a ilegalidades en los permisos de extracción y daño ambiental $l^{4}$. Un mes antes de la votación sobre

\footnotetext{
3 Intervención de la diputada Mirna Patricia Pérez Hegg.

4 El pronunciamiento de la Sala Constitucional tuvo lugar el 19 de junio de 2013. Por unanimidad, la Sala acordó rechazar de plano la acción de inconstitucionalidad planteada desde noviembre de 2011,
} 
la reelección, en octubre de 2012, Industrias Infinito presentó una recusación contra el magistrado Cruz por - a su criterio- haber externado posiciones contrarias a la empresa. Dos años antes, en abril del 2010, Cruz voto favorablemente un recurso de amparo para detener la extracción de oro de la mina Crucitas. Fue un voto minoritario, entonces sin consecuencias para la empresa minera.

En directa relación con el asunto de la minera, estaban las posibles causas penales contra el ex presidente Óscar Arias Sánchez $y$ el ex ministro Roberto Dobles, en razón del fallo del Contencioso. En noviembre de 2012, los hermanos Rodrigo y Óscar Arias Sánchez mantenían un fuerte ascendente entre los diputados del pln; la mayor parte de la fracción legislativa había apoyado la candidatura presidencial del primero, luego abortada y mantenía una relación de estrecha proximidad con el ex presidente. No era inexacto hablar de facturas por cobrar en esta votación.

Cuando el 20 de setiembre de 2012, la Asamblea Legislativa conoció el comunicado de la Corte sobre el interés de Cruz en ser reelecto, el trámite pasó a la Comisión Permanente Especial de Nombramientos, la cual se reunió en dos ocasiones, una para acordar la forma de trabajo $y$ otra para escuchar al magistrado $y$ hacerle preguntas (ASPAL nro. 68, 2012: 25). En la segunda ocasión, el representante del Partido Acción Ciudadana (PAC), posiblemente con el propósito de provocar una confrontación de posiciones, mencionó "el corrillo" de que la Sala Iv se había convertido de hecho, en un Senado con funciones de co-gobierno. Según el acta de la Sesión Ordinaria nro. 2, del 8 de octubre, tanto la exposición como las respuestas dadas por el magistrado Cruz satisfacieron a las y los integrantes de la comisión, o cuando menos eso parecía. En su presentación, el magistrado Cruz se refirió a la forma ligera en que se hablaba en los medios políticos de un país ingobernable,

argumentando que la Sala I ya había resuelto el tema y por lo tanto, no existía un proceso abierto. La ausencia de la magistrada Calzada y del magistrado Mora, por fallecimiento, posiblemente pesó decisivamente en este nuevo voto del Tribunal Constitucional. sin que ninguna de las personas presentes lo enfrentara o rebatiera. Inmediatamente, después del intercambio, la comisión emitió un informe de mayoría a favor del magistrado Cruz. Solamente, el representante socialcristiano votó negativamente, pero no hubo un informe negativo de minoría, ni el voto adverso quedó fundamentado en el acta.

Además del diputado socialcristiano, en esta sesión de comisión participaron tres representantes del pLn, uno del Movimiento Libertario, uno del pac y una del Partido Accesibilidad sin Exclusión. De ellos, solo el diputado libertario no estuvo en la sesión del 15 de noviembre siguiente. De los firmantes del informe de mayoría, el legislador del pac y la diputada de Accesibilidad sin Exclusión mantuvieron su palabra. Los otros viraron hacia la posición opuesta en las cinco semanas siguientes, sin dar razón alguna.

El 8 de octubre, los diputados de Liberación Nacional tuvieron una oportunidad para sumar sus votos al del diputado socialcristiano y conseguir un informe negativo de mayoría. De haberlo hecho, las posiciones hubiesen estado claras desde el inicio y la discusión subsiguiente transcurrido de otra manera, con otras características. No fue este el camino seguido. El dictamen afirmativo de mayoría estuvo listo diez días antes de vencer el plazo reconocido luego por la presidencia de la Asamblea Legislativa para impedir la reelección automática, todavía había tiempo para ir al Plenario e impedir la reelección de Cruz dentro del plazo posible, por un procedimiento legalmente correcto. La potestad de la Asamblea de no reelegir no estaba en discusión.

Al final del dictamen de mayoría, aparece la indicación de que la resolución se daba: "en el entendido de que finalmente es el Plenario Legislativo quien decide o no reelegirlo" (Comisión Permanente Especial de Nombramientos, 2012: 5), algo que podría interpretarse como una cura en salud, pero que ciertamente es un estribillo de uso frecuente cuando se trata de la elección de nuevos magistrados, cuyo nombramiento depende de una mayoría calificada. Siempre hay dos opciones abiertas, elegir o no elegir. ¿Por qué, en el Plenario, no se aprovechó el plazo antes de que venciera el tiempo 
legal para votar negativamente, la reelección de Cruz? Y antes: ¿por qué aprobar primero un informe positivo de mayoría para luego cambiar de posición? Las intenciones reales se ocultaron entre mensajes equívocos; se podría suponer que a esa altura no se tenían todavía los 38 votos necesarios para votar negativamente. En los debates posteriores al día 15 de noviembre, se dirá en dos ocasiones, sin que nadie lo desmintiera, que una diputada intervino en la votación encontrándose médicamente incapacitada $^{5}$ (aspal nro. 100, 2012: 53). Llevar a una persona con quebrantos de salud a una elección ( $y$ que ella se deje llevar) es un indicador de la importancia dada a la elección, pero también de las dificultades existentes para sumar votos. Sin ella no se hubiesen podido reunir los 38 votos necesarios para impedir la reelección.

Después de la votación, los adversarios de la reelección justificarán su conducta alegando que la decisión del 15 de noviembre pretendió frenar una Sala Constitucional invasora de los campos de competencia del Poder Legislativo y Ejecutivo. Hablarán incluso de una situación de ingobernabilidad alimentada por el poder expandido del Tribunal Constitucional. Dentro de esta lógica, la reversión posterior de la decisión, el día 20 de noviembre, tan solo confirmaba esta tesis: sobre el voto de una mayoría calificada de legisladores, se había impuesto una resolución fundamentada en una sentencia previa de Sala Constitucional y la decisión última sobre la legitimidad del proceso seguido en el caso de Cruz quedaba en manos de esa misma Sala.

Los argumentos esgrimidos por el presidente de la Asamblea Legislativa para anular la decisión del día 15, fueron introducidos en el Plenario Legislativo por el diputado Luis Fishman, después del recuento de votos. Él fue el primero en mencionar la resolución de la Sala Constitucional nro. 2621 del 23 de mayo de 1995, emitida a propósito de la reelección del magistrado Jesús Ramírez Quirós. La sentencia 2621 diferenciaba entre el artículo constitucional que rige la elección de nuevos magistrados (artículo 163) del que organiza la reelección de los mismos (artículo 158). Solo para los

5 Intervención del diputado Juan Carlos Mendoza García. nuevos magistrados y magistradas estaba abierta la opción entre la elección o no elección; para quienes se postulaban nuevamente para el cargo, la alternativa posible se limitaba a la "no reelección". A criterio de Fishman, el tiempo para la decisión sobre el magistrado Cruz había vencido y procedía el nombramiento automático; a su parecer, el día 15 de noviembre se cometió un "error jurídico", evitando referirse explícitamente al motivo del mismo, pero dando a entender la existencia de razones más allá del equívoco o de la chapucería. El sentido que hacía comprensible lo actuado el 15 de noviembre quedaba oculto, cuando menos no coincidía con las razones expuestas a posteriori por quienes la protagonizaron.

La resolución de la presidencia de la Asamblea Legislativa del 20 de noviembre, reposa sobre el principio de que la reelección de un magistrado rige automáticamente a partir de la fecha de vencimiento de su período, salvo que dos terceras partes de la totalidad de los $y$ las congresistas hubiesen decidido antes lo contrario. Un plazo de "treinta días naturales posteriores al vencimiento del período respectivo o de la fecha en que se comunique que ha ocurrido la vacante" aparece indicado en el artículo 163, asumido como válido para elecciones $y$ reposiciones de magistrados. Pero un lapso igualmente preciso no se señala en el artículo 158 , con lo cual quedaba siempre un margen aprovechable para debatir cuál era y a partir de cuándo debía contarse la fecha crítica.

Conforme a la sentencia del 23 de mayo de 1995 de la Sala Constitucional ${ }^{6}$, si dos terceras partes de la Asamblea no se había pronunciado en contra de un magistrado o magistrada con interés en reelegirse, él o ella continuaban en su puesto automáticamente al llegar el día en el cual vencía el nombramiento. Acá hay una interpretación de las intenciones del Constituyente; el camino señalado iba en la dirección de la figura de una magistratura vitalicia, pero dejaba una ventana para ejercitar el derecho de no reelección. En varias reelecciones anteriores, esta tesis había estado presente en los debates de la

$6 \quad$ Sala Constitucional. Sentencia 2621 del 23 de mayo de 1995. Sobre el fondo del asunto, considerando XVIII y XIX. 
Asamblea. La decisión negativa debía tomarse entre el día en que el Plenario conoció la nota sobre el vencimiento de período para el cual fue electo un o una integrante de la magistratura y la fecha en la cual terminaba el nombramiento. A principios de 2009, la presidenta de la Sala Constitucional, Ana Virginia Calzada, fue reelecta de manera automática porque el vencimiento de su nombramiento llegó sin que hubiese una resolución; ella contaba entonces con el apoyo de los partidos que votaron en contra de Cruz, y tenía la oposición del pac.

Pese a lo anterior, también era cierto que la sentencia constitucional de 1995, no había sido acatada siempre de manera consecuente en los doce años transcurridos desde la misma. Después del 20 de noviembre, se recordará que hubo casos de magistrados reelectos con atención al artículo 158 y otros conforme al 163, con plazos contados de manera distinta. Para quienes estaban por la no reelección existían antecedentes que respaldaban y legitimaban el voto del 15 de noviembre. Munición para la discusión se podía encontrar en el párrafo del artículo 163 en el cual se hace mención del los treinta días naturales "posteriores al vencimiento del período respectivo" (ASPAL nro. 100, 2012: 39-41 y 45-47; ASPAL nro. 101, 2012: 12-17)7.

Las diferencias en torno a la interpretación de la ley son propias de toda discusión política; en esta ocasión el choque de posiciones cerró, al menos momentáneamente, un espacio de informalidad-imprecisión presente en otras reelecciones de los y las integrantes de la magistratura. Comprensiblemente, para quienes estaban por la reelección del magistrado Cruz, los precedentes de irregularidades eran errores $y$ tales no generaban derechos.

Hubo un plazo entre el día del pronunciamiento de la Comisión de Nombramientos y la fecha del vencimiento del período del magistrado, lo cual pudo haber sido utilizado por quienes estaban en contra de la reelección de Cruz para actuar antes que entrara

7 Intervención del diputado Martín Monestel Contreras. Allí mismo: Intervención del diputado José María Villalta Flórez-Estrada, pp. 45-47. También: Intervención del diputado Luis Gerardo Villanueva Monge. en vigencia el automatismo. Esta aparente pasividad parece haber tenido un equivalente en las filas opuestas. Ningún diputado o diputada favorable a la candidatura del magistrado evocó antes del día 15 la sentencia 2621 y sus implicaciones: el "hecho insólito" pudo haber sido advertido con antelación y ello hubiese revertido los posibles cursos de acción. Quizá se podría argüir inexperiencia o falta de un asesoramiento adecuado, algo que de ser así merecería ser analizado con detenimiento; sin embargo, tal eventualidad no es suficiente para entender por qué un diputado experimentado esperó hasta después de la elección para advertir sobre el "error jurídico", permitiendo primero su consumación. Nuevamente, faltan elementos para comprender los motivos subyacentes a las acciones $y$ a las no acciones.

En la votación de noviembre de 2012, la Sala Constitucional quedó involucrada desde varios lados en la solución de un asunto de su interés, la reelección de uno de sus integrantes. Primero, por el recurso de amparo inmediatamente interpuesto ante ella contra el "error jurídico" y segundo, por la resolución anterior de la Sala, en la cual se apoyaba el pronunciamiento de la presidencia de la Asamblea. Esta presencia de la Sala Constitucional, dará sostén a la defensa-argumentación desarrollada por la bancada del gobierno después del día 20 de noviembre. Hasta esta última fecha no aparecen (ni tampoco aparecerán luego) en las actas de ninguna razón precisa para oponerse a Cruz específicamente. Contra él no se dijo palabra alguna. Tal vez fue un recurso para evitar la discusión de asuntos tan delicados como el decreto que declaraba la actividad minera de interés nacional dado por el presidente Oscar Arias, las seguridades privadas y públicas que él pidió al nuevo gobierno de su partido para la minera, las irregularidades constatadas por los tribunales en el trámite de los permisos respectivos y más cerca en el tiempo, los indicios de un trasiego de información confidencial desde Sala Primera a la empresa minera por intermedio de un político "un liberacionista histórico" 8 (ASPAL,

8 La condición de "liberacionista histórico" fue subrayada en una nota de la jefa de la fracción liberacionista Viviana Martín, escrita para apoyar 
nro 100. 19/11/2012 y ASPAL, nro 101. 20/11/2012) nombrado como magistrado suplente en el año 2010, el cual laboraba en lo privado para personas vinculadas a Industrias Infinito. En esta ocasión trascendió también que el hijo de uno de los abogados de la minera asistió a una de las magistradas que redactó el fallo sobre Crucitas en la Sala Primera hasta poco antes de ocurrir el trasiego de información; el implicado era además sobrino de un ex vicepresidente de la República obligado a renunciar a su puesto debido a un escándalo político relacionado con la aprobación del Tratado de Libre Comercio con los Estados Unidos.

Para evitar todo esto, pero también como consecuencia del diagnóstico con el que se operaba, quienes objetaron a Cruz llevaron la atención hacia un campo donde resultaba más fácil unir malestares contra la Sala Constitucional. De los corrillos fugazmente aludidos en la Comisión de Nombramientos se avanzó hacia una justificación a posteriori, la cual señala a la Sala IV como una instancia que compromete la gobernabilidad del país. La discusión en torno a la elección fue desplazada hacia el tema de los problemas de la arquitectura institucional gruesa, con la atención centrada en el protagonismo de la Sala Constitucional. Pese a todo, el contexto $y$ el desarrollo de los acontecimientos daban cuando menos una idea de las razones latentes para actuar como se hizo en el caso del magistrado Cruz, así como de las preocupaciones existentes respecto a la composición de la Corte Suprema de Justicia después de la resolución del Contencioso Administrativo sobre Industrias Infinito y de lo ocurrido en la Sala Primera.

En un nuevo nivel se escenificó una lucha por posiciones e influencia presente desde los primeros años del nuevo siglo, la cual se puede seguir en los procesos de elección y reelección de las personas que aspiran a un puesto en la magistratura $y$ en otras instancias institucionales de control (Contraloría General

la candidatura de Moisés Fachler como magistrado suplente de la Sala Primera. Aparentemente, la elección de este magistrado se coordinó desde las oficinas de otra diputada integrante de la fracción del PLN. Al respecto: "PAC advirtió riesgos de nombrar a Moisés Fachler como magistrado suplente". 15/11/2011. En: www.accion.cr/nacionales/politica de la República, Defensoría de los Habitantes). En fechas recientes, tal pugna desembocó en dificultades crecientes para conseguir acuerdos en torno a un nombre $y$ en una prolongación de los plazos para tomar una decisión. La última elección de un magistrado constitucional duró casi un año y medio, $y$ la inmediatamente anterior duró más de un año y nueve meses; en ambas oportunidades el funcionamiento del tribunal quedó comprometido. La causa de la demora era el cambio en el balance de fuerzas en la Asamblea Legislativa provocada por la ruptura del bipartidismo en el año 2002. Como fue mencionado, la magistrada Ana Virginia Calzada fue nombrada por tercera vez en el 2009, en medio de un agitado debate en el cual volvió a salir a flote su elección como magistrada en razón de su estrecha relación políticopersonal con los socialcristianos, el voto a favor de la reelección presidencial, sus votos en la discusión del TLc con los Estados Unidos y más recientemente, el aval a la explotación minera. La creciente complicación de los procesos de elección de los y las integrantes de la magistratura corre paralela al lugar central que venía ocupando el Tribunal Constitucional, posición descrita polémicamente, desde lados incluso opuestos, como la correspondiente a un Senado o una Cámara Alta.

Después del día 20 de noviembre, la Sala Iv fue repetidamente presentada como un cuerpo engrandecido y colonizador, que invadía los campos de los poderes Ejecutivo y Legislativo, estrechándolos y disminuyéndolos. Según esto, la instancia responsable de dirimir conflictos de competencia entre poderes $y$ de hacer valer el principio constitucional de la división de poderes se venía expandiendo con una dinámica propia. No era una imagen nueva, pero era la primera vez que se movilizaba como arma de lucha, en una situación de choque frontal entre los tres poderes de la República.

Usando términos recuperados de la prensa, presentes en el debate legislativo desde un tiempo atrás, una diputada acusó a la Sala Constitucional de "prevaricato" y de "institucionalizar el prevaricato", de una falta a las obligaciones inherentes a un cargo público, y un uso 
arbitrario del mismo ${ }^{9}$ (asPaL nro. 102, 2012: 1415). La figura del cuerpo que abusa de su poder $y$ emite resoluciones antojadizas se integrará, sin diluirse, en otra más extensa, la cual, en su versión reducida dirá que la Sala Constitucional había alterado el sistema de pesos y contrapesos garantes de la división de poderes, en primera instancia en detrimento de la Asamblea Legislativa como depositaria de la soberanía popular $^{10}$ (ASPAL nro. 101, 2012: 20-25). Una variante más extensa de esta posición predica que la Sala iv "se había extralimitado en sus facultades interpretativas e invadido con ello la competencia del Poder Legislativo, del Ejecutivo y de las instituciones descentralizadas...”. Surgió, según esto, "... un súper-poder que legisla y controla los poderes tradicionales", con lo cual el orden constitucional basado en la división de poderes se habría desfigurado hasta transformarse en otra cosa ${ }^{11}$ (ASPAL nro. 102, 2012: 18-24). Urgía sujetar al "super-poder" para restablecer un equilibrio. Las palabras conducen al filo de un precipicio; algo estructural estaba falseado y crujía.

Bajo esta luz posterior, los rumores apenas mencionados en la Comisión de Nombramientos el 8 de octubre, cobran otras dimensiones. Seis meses antes, la Presidenta de la República había criticado a la Sala Constitucional por haberse convertido, ilegítimamente, en una Cámara Alta que bloqueaba la aprobación de leyes, refiriéndose entonces a la admisión de la acción de inconstitucionalidad que dio al traste con el proyecto de reforma fiscal y antes, a las resoluciones de la Sala sobre la ley de tránsito y las acciones de inconstitucionalidad admitidas por violentar el principio de racionalidad y proporcionalidad reconocido por todas las Cortes Constitucionales (Villalobos, 15/4/2012). En el mes de mayo de 2013, cuando surgió la idea de la Comisión de Notables, la presidencia de la Sala iv se vio obligada a negar que el Tribunal Constitucional

9 Intervención de la diputada Damaris Quintana Porras.

10 Intervención del diputado Fabio Molina Rojas.

11 Intervención del diputado José Roberto Rodríguez Quesada. se hubiese convertido en un cuarto poder "en guerra" con la Presidencia y llamó la atención sobre un hecho reconocido desde principios del nuevo siglo, el continuo desplazamiento hacia la Sala de los problemas no resueltos por los poderes Ejecutivo y Legislativo; con esto la responsabilidad era devuelta a la llamada clase política; en esta variante, el activismo del Tribunal Constitucional sería entonces síntoma y no causa (Ramírez, 2012).

Más hacia atrás, pero siempre en la proximidad, estaba el proyecto de reforma presentado en el segundo semestre de 2010, cuyo objetivo era un recorte de las atribuciones de la Sala Constitucional y la eliminación del control político, al disponer que actos específicos del Gobierno y la Asamblea Legislativa no podían ser objeto de acciones de inconstitucionalidad. En esta oportunidad, la presidenta de la Sala Constitucional advirtió el peligro de crear "zonas de impunidad" contrarias al Estado de Derecho. Liberación Nacional promovió activamente este proyecto; su defensor fue el diputado Francisco Chacón, uno de los arquitectos del proceso de apertura comercial, quien para noviembre de 2012 se había convertido en asesor $y$ hombre de confianza de la presidenta, con el cargo de Ministro de Comunicación. Antes, en el 2009, uno de los promotores de la reelección presidencial propuso reformas a la Ley Orgánica de Contraloría General y a la Ley de Control Interno, por las excesivas potestades concedidas al órgano contralor en materias supuestamente ajenas a su competencia constitucional $y$ volver a definir las atribuciones de la Sala Constitucional. La idea era acabar con la ingobernabilidad presentada como la dictadura de los órganos que no tienen origen directo en la voluntad popular (Hernández, 2009: 15).

La justificación a posteriori de la no reelección del magistrado Cruz, buscó capitalizar un estado nacional de malestar e insatisfacción nacional con las instituciones públicas. Durante los últimos 30 años, las columnas del Estado Benefactor habían sido descalificadas, debilitadas y también usadas como palanca a favor de innovaciones urgentes, supuestamente postergadas o no llevadas consecuentemente hasta el final. Tal proceso ha transcurrido en medio 
de tensiones políticas y jurídicas, en paralelo a la conformación de uno de los países económicamente más abiertos de América Latina. A la lista de los cuerpos necesitados de ingeniería (en la cual han estado la banca nacional, la educación, el área estatal de la energía y las comunicaciones, los seguros y el sistema de salud), al cierre de la primera década del siglo xxı, se agregó de manera explícita la Sala Constitucional y el Poder Judicial.

Al terminar el siglo anterior, el Poder Ejecutivo intentó modificar la Ley Orgánica de la Contraloría General de la República, con el fin de reducir su radio de intervención en operaciones con fondos públicos y limitarla para pronunciarse sobre la oportunidad, eficacia o conveniencia de las acciones controladas. El Ejecutivo buscaba un mayor espacio para sí, a criterio de la Contraloría; sin embargo, la iniciativa violentaba la Constitución Política y creaba peligrosos espacios de incertidumbre. Por lo tanto, las propuestas de reforma presentadas por la misma Contraloría chocaban con la falta de ambiente político para ser aprobadas. Casi al mismo tiempo, el Poder Ejecutivo pretendió reformar la Ley General de Administración Pública en aras de romper el resentido bloqueo institucional. La idea fue detenida por la Sala Constitucional, la cual advirtió el peligro de un posible avance hacia "la eficiencia de las dictaduras".

Siete meses antes de estos hechos, la Sala Constitucional se había pronunciado en contra de la llamada "Ley para el mejoramiento de los servicios públicos de electricidad y comunicaciones". Los magistrados constitucionales objetaron el trámite y el contenido de la misma. La reforma publicitada como un gran salto adelante, creaba un confuso sistema de cuerpos público-privados que escapaban al control de las instituciones responsables, significaba una privatización-oligarquización anticonstitucional del patrimonio público (Solís, 2006). Un antecedente de este intento fallido fue el freno a la privatización encubierta del Instituto Costarricense de Electricidad, en 1994 (el caso Millicom), también mediante un voto de la Sala Constitucional. Común denominador en estos y otros ejemplos, es la disolución de límites entre lo público y lo privado. Desde estos años, el martilleo sobre la institucionalidad existente va en una misma dirección: reducir el espacio de los órganos de control, achicar la cerca que limita el campo de sus atribuciones y propiciar estructuras híbridas, sin control.

Después de los reveses del año 2000, los cuerpos que debían ejercer funciones de vigilancia de los poderes públicos (Contraloría, Defensoría, Procuraduría y Sala Constitucional) adquirieron una importancia central para los partidos políticos comprometidos con la apertura económica y la llamada reforma del Estado. En el lenguaje antes empleado, estas eran las instancias cuya composición no dependía directamente de la elección popular, sujetas a decisiones emanadas de la Asamblea Legislativa. Cada vez más, el debate se concentrará en torno al tema del exceso o falta de control, $y$ la dirección en que lo uno y lo otro se aplica o no se aplica. Comprensiblemente, surge con renovada fuerza la preocupación por las personas que van a ser nombradas en posiciones estratégicas.

La palabra control es clave para entender la oposición cerrada al magistrado Cruz. A la vez, este caso muestra el nivel o intensidad de control pretendido. Cruz había sido una voz disidente, pero siempre estuvo en minoría. Nunca fue un obstáculo, si se entiende por tal una persona que lograba unificar alrededor de sus posiciones a un sector mayoritario de la Sala Constitucional. Su divergencia, como en su momento la del magistrado Armijo, ha tenido un carácter político moral, en tanto coloca algunas de las decisiones más polémicas bajo una luz estrictamente política e interesada y por tanto, les quitaba la cobertura legal-majestuosa-objetiva con la cual han pretendido recubrirse. Aunque fuese por contrate, la disidencia dejaba ver sombras preferibles de ocultar.

\section{UN SEGUNDO HECHO INÉDITO}

La no reelección del magistrado Cruz, el hecho inédito anunciado, estuvo acompañado por un segundo acontecimiento sin precedentes, no anticipado por nadie. El 22 de noviembre el presidente de la Corte Suprema de Justicia e integrantes de la magistratura encabezaron una manifestación a favor de la independencia judicial. El hecho marcaba un 
hito, tanto por los protagonistas como por el tema puesto en el primer plano: el de un Poder Judicial acorralado en su independencia $y$ un Estado de Derecho en peligro.

En primera instancia, la amenaza a la cual reaccionaba la Corte Plena no provenía del exterior (de una des-estabilización originada allende nuestras fronteras) ni de abajo (una subversión desde la base de la sociedad) sino, desde dentro y desde arriba. Partía de dos de los poderes que le dan forma a la institucionalidad reconocida $y$ de unas fuerzas sin contornos precisos, denominadas "oscuras o fácticas", con el peso para hacerse sentir dentro de los órganos fundamentales de gobierno. Posiblemente, esta fue la primera vez que uno de los poderes del Estado marchó para ponerle un límite a otro constitucionalmente colocado a su mismo nivel. En un nivel, podría hablarse de un acto de resistencia desde la legalidad y la Constitución, para detener una acción que las lesionaba, la cual partía de los otros dos poderes del Estado.

Quien con más decisión advirtió el peligro y lo describió, fue el presidente de la Corte, Luis Paulino Mora Mora, en la sesión del 19 de noviembre, cuatro días después de la no reelección del magistrado Cruz en su Discurso de la Silla Vacía (Acta nro. 40-12, 19/11/2012) ${ }^{12}$. A su entender había un objetivo expreso: conseguir una magistratura complaciente con los intereses de grupos y personas específicas. No solo el Tribunal Constitucional se había convertido en una presa apetecida; en la misma condición quedaba la Corte Suprema, pieza clave de la cual dependían los demás tribunales, funcionarios y empleados del ramo judicial. Mora recordó además que la Corte era a su vez la llave de acceso a la Fiscalía General de la República y al Tribunal Supremo de Elecciones. Las palabras del magistrado Mora, tomadas en toda su seriedad, señalaban un (nuevo) intento por minar o vaciar el sistema político de controles. Se estaba ante una subversión de los marcos constitucionales, promovida por las corrientes más identificadas con la ideología del mercado abierto.

En el contexto de los procesos penales recién concluidos contra figuras de primera fila

12 Intervención de Luis Paulino Mora Mora. Presidente de la Corte Suprema de Justicia. de la clase política y de los nuevos que se vislumbraban, la integración de las cuatro salas de la Corte y de los Tribunales Contenciosos había adquirido una importancia de primer orden. La resolución de un contencioso, divergente de un pronunciamiento anterior de la Sala Cuarta, se trajo abajo la concesión a Industrias Infinito y dejó a un otro ex presidente de la República ante la posibilidad de un juicio penal. En la última década, la Fiscalía General de la República había pasado a tener un lugar clave en razón de los procesos seguidos a dos ex presidentes; al cierre del año 2012, ella tenía causas en trámite contra 18 altos funcionarios públicos, entre ellos políticos reconocidos, por motivos tan diferentes como abusos de autoridad, incumplimiento de deberes, tráfico de influencias, administración en provecho propio, prevaricato, enriquecimiento ilícito, malversación, peculado y falsedad ideológica. Las denuncias provenían de la Contraloría y la Procuraduría, de la prensa y de la ciudadanía. Simultáneamente, irregularidades constatadas por el Tribunal Supremo de Elecciones ponían a otras figuras públicas (dirigentes políticos o personas cercanas a ellos) al alcance de los tribunales y las llevaban a buscar caminos de evasión, entre los cuales se perfila la inmunidad parlamentaria, cuando menos para ganar tiempo. Los tribunales no solo cerraban o abrían las puertas de una aspiración política o de una oportunidad económica, esas puertas podían ser también las de la cárcel para un sector social y político incapaz de imaginar algo semejante unos pocos años atrás.

En la sesión extraordinaria de la Corte Plena del 19 de noviembre, se escucharon palabras nunca antes dichas, cuando menos con la conciencia de que eran públicas y estaban siendo seguidas con atención. La presidencia de la Corte señaló directamente a los políticos que "meten la mano en la justicia" y recurren a "burdas excusas" para conseguir una línea de acción complaciente con sus intereses. Sobre aquellos se puso la responsabilidad del deterioro de los espacios tradicionales de mediación social y de la falta de un proyecto político e ideológico coherente, en caso de que el objetivo fuese una sociedad que produjera con eficiencia y repartiera con justicia, en la cual se buscara 
la equidad y el respeto a la dignidad humana. Incluso, alertó respecto a nuevas campañas para debilitar el prestigio de la magistratura $y$ la justicia: “...tengo información para mi creíble que eso se está tramando en este momento. Hay fuerzas oscuras que han cohonestado este triste episodio de nuestra historia..."13. El presidente de la Corte habló de una conspiración contra el Poder Judicial y en este contexto puso lo sucedido con el magistrado Cruz.

Tales palabras fueron pronunciadas por una persona acostumbrada a mantener la compostura en trances difíciles, ejercitada en el autocontrol, entrenada en sopesar muy bien los términos usados. Iban dirigidas, en primer lugar, contra la cara inmediatamente visible de las llamadas "fuerzas oscuras", los diputados de Liberación Nacional y en particular el jefe de su fracción legislativa, el cual días antes había afirmado que la votación en contra de la reelección del magistrado Cruz había sido un mensaje y una llamada de atención a la Sala Constitucional, "para que se alineara". Los términos displicentes del diputado subvertían el sistema de división de poderes establecido en la Constitución Política; en vez de tres Poderes distintos e independientes entre sí, cada uno con funciones propias y no delegables, como lo establece el artículo 9 del texto constitucional, lo predicado es un sistema de poderes alineados o sincronizados, con-fundidos unos con otros.

Inevitablemente, este comentario creo indignación y generó una reacción. Pronunciadas de manera tan descarnada eran un golpe frontal contra el Poder Judicial y una agresión al gremio judicial; incluso quienes simpatizaban con la posición política del diputado se veían colocados en un aprieto. Cinco meses más tarde, el mismo diputado terminaba de redondear su idea, al sumar a lo antes dicho, que los y las integrantes de la magistratura debían promover un "clima de negocios" (Semanario Universidad, 03/04/2013). En esta dirección iba entonces la coordinación deseada.

Vistas en conjunto, las transformaciones económicas y sociales vividas por el país desde mediados de los años 80 podían describirse utilizando la palabra negocios; lo favorecido por la
Ibíd. apertura neoliberal ha sido el aprovechamiento indiscriminado de toda oportunidad para hacer negocios en nombre del mercado libre. Mercado $y$ negocios, dos palabras distintas, se han convertido en sinónimos. A la vez, los negocios y corrupción-política se habían venido aproximando cada vez más entre sí desde las últimas décadas del siglo pasado; un punto de inflexión en este sentido fue la reforma a la ley de energía $y$ comunicaciones, antes aludida, detenida por una movilización social en abril del 2000. En aquel momento, la legalidad y la Constitución fueron defendidas por la ciudadanía que rechazó un cambio ofrecido como una gran innovación, el cual iba en dirección de una privatización en beneficio de los sectores políticos que lo promovían y los intereses articulados en torno a ellos. Una confirmación de lo entonces sospechado llegó poco después, con los procesos penales contra dos ex presidentes y la salida-huida del país de un tercero por un largo tiempo; dos de ellos hicieron negocios con la institución que no pudieron transformar conforme a lo deseado en el $2000 y$ otro con la seguridad social.

Ahora bien, este cuadro tenía otros aspectos importantes de atender. De los 20 magistrados y magistradas presentes en la sesión de la Corte del 19 de noviembre, 11, la mitad más uno, tomaron la palabra y convinieron en que la no reelección del magistrado Cruz, en las condiciones en que ocurrió, significaba un ataque directo contra el Poder Judicial y los principios e instituciones que forman la vida democrática. La lectura del acta de la sesión muestra cómo alrededor de la intervención del presidente de la Corte, se formaron varias órbitas distintas, aparentemente complementarias. Muchas apelaron al imaginario del país excepcional $y$ desde él presentaban lo recién ocurrido como un descenso o caída, hacia lo conocido en otros países de América Latina, algo inconcebible entre nosotros (Acta nro. 402012, 19/11/2012) $)^{14}$. Repetidamente, la voz de

$14 \quad$ Intervención del magistrado Gilbert Armijo. Todavía en el año 2006, los índices de independencia $y$ de confianza en el Poder Judicial costarricense, lo colocaban entre los primeros lugares de América Latina, en el grupo de los países mejor evaluados. Una parte importante de esta reputación estaba afectada positivamente por el juicio seguido contra dos ex presidentes. 
las y los integrantes de la Corte Suprema fue alzada para expresar indignación y enojo. Desde este estado emocional se coincidió en el paso siguiente, llevar el malestar y la protesta a un espacio inusual para las y los togados, tradicionalmente asociado con los trabajadores, los sindicatos $y$ los estudiantes para protestar contra los otros dos poderes de la República. Incluso la presidenta de la Sala Constitucional escogió explícitamente el escenario de la calle para dar la pelea por la independencia del Poder Judicial (Acta nro. 40-2012, 19/11/2012) ${ }^{15}$.

Existen indicios para suponer que no todos los y las integrantes de la magistratura que hicieron uso de la palabra, expresaron lo que realmente pensaban o lo que hubiesen dicho o hecho si la posición de la presidencia de la Corte hubiese sido distinta. Posiblemente, algunos y algunas no querían ser solidarios con Cruz, pero se vieron obligados a serlo, a su pesar. Lo mismo cabe presumir que sucedió entre ese $45 \%$ que se mantuvo en silencio. No todos los que hablaron y no todos los que guardaron silencio tomaron parte en la manifestación convocada para defender la integridad del Poder Judicial, el reto inmediato urgente. Solo una tercera parte de las personas integrantes de la magistratura lo hizo. Hubo quienes antepusieron otros compromisos, lo cual deja abierto un campo para especular sobre su lectura última de lo que estaba en juego. Las distintas valoraciones de las tareas y retos del Poder Judicial se entretejieron en este momento con simpatías $y$ deudas políticas, así como posiblemente también con cálculos personales y grupales de mediano y largo plazo.

Habría que volver a revisar estos sucesos a la luz de otros posteriores que afectarán a la dinámica de la Corte Plena, particularmente, lo sucedido después de la muerte de su presidente, el magistrado Mora Mora. A la vez, en otra dimensión importante de diferenciar, hay elementos para pensar que algunos funcionarios medios y altos del Poder Judicial, es decir, la unidad alrededor de la Corte Suprema, no dejaba de ser problemática. Algunos y algunas

15 Intervención de Ana Virginia Calzada. Presidenta de la Sala Constitucional. resentían un desfase entre la reivindicación externa, la independencia del Poder Judicial y su experiencia en esta materia con la misma Corte. Su posición en la estructura judicial les inducía a tomar distancia de la manera en que quedó planteado el conflicto.

En otro plano, el choque entre la Asamblea Legislativa y la Corte se expresó en una toma de posición ante términos cuya carga política y sus implicaciones no había sido tan manifiesta en la discusión pública. El lenguaje de la gobernabilidad-ingobernabilidad pasó a un lugar destacado y sirvió para separar aguas entre los tres poderes en pugna.

La manera ligera como se hablaba de un país ingobernable fue criticada por $\mathrm{Cruz}$ en la Comisión de Nombramientos, sin que nadie recogiera el reto lanzado. Referencias explícitas e implícitas a la gobernabilidad y la ingobernabilidad aparecen en la discusión legislativa de estos días, la mayoría de las veces como parte de los argumentos que legitimaban lo actuado el 15 de noviembre. En los días siguientes, la palabra gobernabilidad reapareció también entre las y los integrantes de la Corte con acentos claramente problemáticos. Las primeras líneas de la pensada intervención de Luis Paulino Mora destacaban que la justicia y la ley estaban siendo vistas como un estorbo para la gobernabilidad, resaltando una tensión entre lo uno y lo otro. Él sostendrá que el concepto de gobernabilidad había sido "manipulado" y "mal entendido" en detrimento del Estado de Derecho; colocó la ingobernabilidad imputada en la Asamblea Legislativa a la Sala Constitucional, en la clase política y en los imprecisos poderes fácticos; asimismo — de manera más amplia"en el colapso de estado bienestar" y en la incapacidad para sostener el pacto social de 1949, mediante políticas congruentes $y$ adecuadas. La fractura del acuerdo social sintetizado en la Constitución fue relacionada con la debilidad de las instituciones democráticas de representación, el deterioro de los espacios tradicionales de mediación y por ello, con un fracaso de la política. Desde esta perspectiva, palabras como gobernabilidad e ingobernabilidad quedaban como el ariete con el cual golpeaba la puerta una clase política sin un proyecto de convivencia social. 
Aunque no lo menciona explícitamente, el presidente de la Corte evoca la figura de un Caballo de Troya diseñado para penetrar en los terrenos todavía vedados por la Carta Fundamental.

Para algunos, la Constitución parece ser un conglomerado de leyes posibles de modificar u orientar en aras de la gobernabilidad, mediante una operación de ingeniería jurídico-institucional; en tal caso, el valor gobernabilidad pasaría a convertirse en el primero y superior, una decisión política delicada ya que - como es subrayado en la literatura sobre el tema- las palabras gobernabilidad, democracia y Estado de Derecho no son equivalentes, así como existe la eficiencia de las dictaduras también existe la gobernabilidad autoritaria. Si la palabra democracia no aparece o está desdibujada, ¿dónde estaría la frontera entre la gobernabilidad y el autoritarismo? Una segunda posibilidad consiste en ver la Constitución como la expresión de un pacto social de convivencia, articulado bajo principios $y$ valores considerados fundamentales e inalienables, los cuales son, en una dimensión sustancial, parte de un largo legado civilizatorio y democratizador, en tanto han ido cristalizando, cobrando vigencia y llenándose de contenido en el curso de un proceso histórico, nacional e internacional. En este caso, el valor gobernabilidad tendría otro lugar, no sería el mayor ni el más importante. Cuando menos se requerirían algunos cuidados políticos importantes para hablar de esta.

Este segundo punto de entrada fue al menos invocado en la intervención de Mora, el cual se refirió al deterioro de los espacios de mediación social y la debilidad de los órganos de representación política, la criminalización de la pobreza, la falta de políticas de atención y prevención de los sectores más vulnerables, y la fractura del pacto social. Cuando él habla de una colectividad que "clama por justicia social", emplea palabras que obligan a pensar en los macro indicadores que mostraban un estilo de transformación social-institucional que venía ensanchando y crispando las distancias sociales. Son apreciaciones que se pueden llenar de contenido empírico: a comienzos de la segunda década del siglo xxi, Costa Rica era el país centroamericano donde la desigualdad crecía con más rapidez; en los hechos, se alejaba de una idea de convivencia democrática y de democracia social, al mismo tiempo que decrecía el apoyo al sistema político.

Con acentos de tonalidad conservadora, en el sentido de cuidar un legado, también el magistrado Cruz Castro abordó el tema de la Constitución como expresión de un pacto de convivencia anclado en una historia. Lo hizo en su presentación del 8 de octubre, al desarrollar la idea de que la institucionalidad existente "...ha sido construida por muchos costarricenses destacados y anónimos que nos han heredado un país singular...", y volvió a él en la intervención ante la Corte, el 26 de noviembre de 2012. En esta segunda ocasión, colocó las palabras gobernabilidad-ingobernabilidad como piezas de un lenguaje cifrado dirigido a debilitar los mecanismos de control existentes. Lo que Mora denunció como la expresión de un "estilo autoritario", toma aquí una figura claramente negativa, llamada por el magistrado Cruz la democradura o dictadura en democracia (aspal nro. 41-2012. 26/12/2012) ${ }^{16}$. Aunque no se hace explícito en el texto, el segundo de estos términos ha estado relacionado en la discusión nacional con el ex presidente Oscar Arias y con el PLN del siglo xxi.

En estas dos intervenciones queda sugerido un vínculo entre el lenguaje de la gobernabilidad-ingobernabilidad $y$ un filón autoritario, o cuando menos un impulso que puede ir en contra de los principios del Estado de Derecho. Como se puede evidenciar, hasta el 15 de noviembre, las intenciones de impedir la reelección del magistrado se ocultaron. A partir del día 20, el paso a la posición contraria fue justificado apelando al prevaricato, al súper poder $y$ al motivo de la ingobernabilidad, a todo lo cual se le arrimó la tesis del número como indicador fuerte de la democracia: los treinta $y$ ocho diputados $y$ diputadas que conformaron la mayoría calificada representaban la voluntad de millón y medio de personas registradas en el

16 Intervención del magistrado Fernando Cruz Castro. 
padrón electoral, y eso los facultaba para ejercer un veto político discrecional sin necesidad de una argumentación previa, no requerida en nuestro ordenamiento legal. Gobernabilidad era el derecho de la mayoría popularmente electa para actuar; la ingobernabilidad es el resultado de los obstáculos interpuestos en el camino de la mayoría electa. Luego, el bloque mayoritario de diputados debería actuar sin impedimentos, representaba al grueso de la población que acudió a las urnas.

Tal dirección y énfasis de la argumentación parece haber sido la que hizo advertir a la magistrada Calzada sobre un "...uso de las instituciones democráticas para fines no democráticos". La pregunta de fondo es entonces si el número es suficiente para calificar un acto de democrático o si bien, una democracia se puede pervertir cuando se ejercita el poder del número sin poner a prueba la consistencia de los argumentos o si el debate no está empapado, en alguna medida, de la voluntad de persuadir o convencer con razones y si no existen condiciones mínimas para ello, a las cuales pertenecería, entre otras cosas, la disposición política $y$ subjetiva para el intercambio de ideas. Sin lo último, las palabras ausentes (o a posteriori) se pueden transformar en medios para justificar la imposición, apelando a la mayoría.

Sobre este mismo punto insistió también el magistrado Arroyo Gutiérrez, presidente de la Sala Tercera, quien se tomó su tiempo para subrayar la distancia que podía abrirse por un lado, entre el criterio de mayoría y por otro, entre la justicia y la razonabilidad (Acta nro 40$12,19 / 11 / 2012)^{17}$. La magistrada y el magistrado concordaban en que, especialmente en la esfera de los poderes públicos, la exposición de las razones y motivos no puede ser sustituida por una mayoría silenciosa o mecánica. Cuando no se argumenta la pertinencia $y$ la necesidad de un acto político, el mismo termina por degradarse, puede transformarse en excusa $y$ arbitrariedad. Acá se subraya la importancia de la palabra; se toca un punto sumamente delicado, entre otras

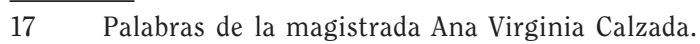
Presidenta de la Sala Constitucional. Allí mismo: Intervención del magistrado José Manuel Arroyo. Presidente de la Sala III. cosas por una larga tradición que iguala llanamente el número y la democracia.

Se puede recordar que hubo un sector de la Corte que no hizo uso de la palabra el día 19 y que por lo menos conforme al acta, guardó silencio. Igualmente, que la debilidad o ausencia de la palabra con contenido es una característica de nuestro debate legislativo y tal vez un rasgo fuerte de nuestro sistema político.

Las palabras del Presidente de la Corte el día 19, fueron directas y tenían destinatarios reconocibles. Nadie las rebatió. Una forma de atemperarlas sin romper la solidaridad de grupo, consistió en colocar lo sucedido el día 15 en una secuencia de hechos parecidos, aunque con otros desenlaces. El magistrado Jinesta Lobo fue quien expresó esta posición: dos veces va a repetir él que lo ocurrido con el magistrado Cruz "era la crónica de una muerte anunciada”. Para él, la no reelección de Cruz estuvo prefigurada en las votaciones para la reelección de los magistrados Mora Mora y Solano Carrera, de la magistrada Calzada, del magistrado Armijo y en su propio caso. Un elemento común sería el cobro de facturas por parte de los políticos. La tesis de la revancha-vendetta-cobro de facturas apareció también en la Asamblea, del lado de quienes apoyaron a Cruz, pero en boca de este magistrado $y$ en este otro contexto, adquiría distintas connotaciones. En setiembre de 2010, después de ser reelecto como magistrado con veinte votos en contra, Jinesta Lobo denunció una persecución política en razón de sus concepciones ideológicas y su visión de mundo; sus perseguidores, dirá en esta ocasión, fueron los diputados de los partidos Acción Ciudadana, Frente Amplio y Accesibilidad sin Exclusión, el bloque del cual salieron los votos a favor de Cruz (Mata, 2010: 6) ${ }^{18}$.

Como se puede seguir en las actas de la Asamblea Legislativa, las reelecciones anteriormente mencionadas estuvieron precedidas o acompañadas de intensos debates sobre la forma en que votaron $y$ actuaron estos magistrados en coyunturas álgidas para el país, en tanto marcaban su futuro y tal vez su destino. Repetidamente, aparecen mencionados el viraje de la Sala Constitucional en el caso de la

$18 \quad$ Entrevista a Ernesto Jinesta Lobo. 
reelección presidencial, las resoluciones de la Sala Constitucional sobre el Tratado de Libre Comercio y la agenda de implementación, y el voto en la Sala Constitucional a favor de Industrias Infinito, casos en los cuales la decisión de mayoría había sido afirmativa. El magistrado Jinesta formó parte de esta mayoría y su reelección quedó cruzada por estas circunstancias políticas, igual que la de sus colegas; su voto contribuyó a despejar el tema de la reelección presidencial, el cual se había convertido en un problema estratégico, luego del fracasado intento de reforma de la ley de energía y comunicaciones en el 2000.

Se presenta otra vez a un Tribunal Constitucional transformado en un campo de la lucha política en el curso del alejamiento, ruptura o reconversión del orden social e institucional amarrado por la Constitución de 1949. En torno a este actor estratégico, existen cuando menos tres niveles de tensiones identificables: el nivel correspondiente al pacto social y político sintetizado en la Carta Fundamental, lo cual conduce a la pregunta sobre la vigencia o caducidad de los valores que informan el texto constitucional; el segundo nivel corresponde al lugar $y$ las atribuciones de la Sala Constitucional, lo cual conecta con la pregunta sobre lo que la Constitución vigente permite o prohibe, esquina desde la cual tocamos nuevamente al asunto de la contribución de la Sala Constitucional a la gobernabilidad o la ingobernabilidad del país $y$ para finalizar, en el tercer lugar se encuentra el nivel de la composición del tribunal propiamente, la cuestión de quiénes llegan o salen de él y por consiguiente, el asunto de los amarres o compromisos, formales e informales, que se gestan en el camino de la elección de las y los integrantes de la magistratura $y$ la manera en que aquellos pueden comprometer este ejercicio.

Cabe preguntarse entonces si tan irregular terreno no se aplana artificialmente cuando se coloca todo el acento negativo en los castigos (nada se habla de las recompensas) a quienes, en razón de sus ideologías, no comparten la visión del mundo de determinados partidos políticos. Tal énfasis opaca la reflexión más amplia sobre el horizonte de sociedad $y$ de convivencia con el cual actúa, especial, pero no exclusivamente, la magistratura constitucional, una dimensión política cuya incorporación franca le daría otra tonalidad al debate $y$ tal vez ayudaría a pensar en otras formas de elección de las personas que conforman este cuerpo.

Desde la sola perspectiva de una magistratura que realiza un trabajo técnico-jurídico, mediado por una ideología "personal", el resultado inevitable serán "las muertes anunciadas"; siempre cabe esperar una tensión entre lo personal y lo político partidista. Desde este abordaje, las y los magistrados quedan en una posición de víctima. El otro lado de la medalla, las implicaciones y los alcances de las afinidades entre quienes integran la magistratura y los partidos (o sectores en ellos) y eventualmente, los acuerdos y compromisos entre unos y otros quedan fuera del horizonte. Algunas carreras hacia la magistratura se construyen desde la complacencia, con el envío de señales fuertes por parte de él o la postulante a los partidos mayoritarios, para persuadirlos de ser la persona adecuada para el puesto. Parte de la discusión planteada desde principios del nuevo siglo versa justamente sobre la forma en que los organismos de control pueden $y$ han sido influenciados y modelados por los intereses políticos $y$ económicos más poderosos. Así como los partidos pueden coordinar un no, también pueden coordinar un sí; dicho en el lenguaje usado en la Corte Suprema, la pregunta era hasta dónde podía llegar la larga mano de los intereses fácticos y de qué manera se hacía sentir.

La intervención del magistrado Jinesta estuvo dirigida contra los políticos, sin distinciones y por ello, tenía un lado atractivo. Podía resonar en el estado nacional de disconformidad con los partidos políticos, las instituciones en las cuales menos confía la población en la primera década del siglo xxi. Alrededor de esta posición podían coincidir muchos de las y los integrantes de la magistratura, en tanto aquí se toca una veta de temor $y$ de resentimiento nacida de la experiencia de haber pasado o tener que pasar, una o varias veces por el espinoso arco de los partidos políticos y la Asamblea Legislativa. Parte de este malestar se ha expresado como un disgusto contra los partidos y las contaminaciones ideológicas. 
En el año 2011, el magistrado electo en la Sala ıv, Paul Rueda Leal insistió con vehemencia en su condición de hombre sin bandera partidaria, distante de todas las ideologías. Un deslinde fuerte que termina subrayando la necesidad de un blindaje político de la Sala Constitucional, tal vez relacionado con las peripecias surgidas en su camino hacia la magistratura, iniciado en el caso de Rueda unos ocho años antes (Murillo, 2011: 6 A). En el 2004, cuando concursó sin éxito para una vacante en la Sala Constitucional, Rueda fue expuesto como una persona favorecida por los socialcristianos en la Comisión de Nombramientos; se afirmó incluso que sus contrincantes fueron mal calificados para favorecerlo (ASPAL nro 54, 16/08/2004: 24, 25 y 34). Se destacó con fuerza una afinidad política; en el 2010, el nuevo magistrado consiguió una concertación de votos pero tenía una razón adicional para enfatizar en su condición de hombre sin partido y al margen de las ideologías políticas; al iniciarse la discusión de los nombramientos en el plenario una diputada liberacionista anunció que se abstendría de votar, por ser ella su suegra. La prensa tomó nota de este hecho, era un dato importante en una cultura política donde los vínculos de parentesco siguen teniendo un papel central (Diario Extra, 22/11/2010: 8).

En la sesión del día 19, la posición del magistrado Jinesta se traslapó parcialmente con la del Presidente de la Corte. Una y otra convergieron, pero también tenían distintas consecuencias prácticas inmediatas. La posición del primero diluye el adversario inmediato a enfrentar, borra su perfil particular, concluye que todos los gatos políticos son igualmente pardos y actúan conforme a su naturaleza, en este caso, desconociendo o violentando el derecho de las y los magistrados a tener una visión del mundo propia. Acá desaparece el hecho que el acceso a las magistraturas está filtrado por un proceso político, el cual, como está estructurado, conlleva lazos, compromisos y a veces también deudas o incluso encargos, que pueden mediar de distintas maneras en el ejercicio de la función pública, un lado que no se puede subsumir sin problemas en el derecho a tener una ideología personal. Las personas interesadas en una magistratura difícilmente pueden escapar de esta dinámica. Ellas no son solo víctimas, también son actores con intereses. En aras de la honestidad y la transparencia, la cuestión del entramado político-partidista tendría que plantearse de una manera más radical y frontal, como un problema político mayor que condiciona las particularidades, límites y posibles perversiones del mecanismo de elección de las $y$ los magistrados. Sobre el acento del derecho a la ideología propia está el asunto, igualmente delicado, de la forma de posesionarse ante los derechos protegidos por la Constitución y muy particularmente, lo que hoy se entiende como los derechos universales o fundamentales.

Enfatizar en la posición del magistrado perseguido, no solo es inexacto sino puede llevar a soluciones insólitas. A mediados de marzo de 2012, la prensa dio a conocer que en la agenda de la Corte Plena se encontraba una propuesta de pago de un plus salarial a los integrantes de la Sala Constitucional, en razón del "riesgo político" al cual estaban expuestos. La idea había sido del magistrado Jinesta; la presidenta de la Sala Cuarta presentó el proyecto ante el Consejo de Personal en octubre de 2010, donde estuvo hasta enero de 2012, cuando fue votado negativamente. Pero supuestamente debido a un error o descuido, el proyecto quedó en la agenda de la Corte; allí se le descubrió a principios de 2012, ocho meses antes del proceso de reelección del magistrado Cruz. El plan del plus salarial llegó al Consejo de Personal poco después de la reelección del magistrado Jinesta $y$ de sus declaraciones sobre la persecución de la cual era objeto por motivos ideológicos (Miranda, 2012: 15). Cuando fue descubierto en la agenda de la Corte, la presidenta de la Sala Constitucional justificó la iniciativa arguyendo amenazas por la posición de la Sala iv ante la invasión de Irak; el Tribunal Constitucional se opuso a la decisión del ex presidente Abel Pacheco de incluir a Costa Rica en la lista de países integrados en la alianza invasora de Irak. La debilidad del argumento dio motivo para comentarios sarcásticos y editoriales amonestadores que abordaban el tema de los privilegios y recordaron que la magistratura ya tenía un sobresueldo de un $30 \%$ en razón de sus funciones. Materialmente, ya que de eso se 
trataba, la magistratura se encontraba bien protegida. Finalmente, el magistrado Jinesta salió a la prensa $y$ volvió sobre el punto conocido: su preocupación por las represalias contra las y los magistrados al momento de la reelección y las reprimendas de las que eran objeto por su posición política e ideológica al resolver los asuntos puestos a su consideración. El magistrado hizo de la vulnerabilidad de las víctimas la razón para una ganancia secundaria, en la forma de un beneficio monetario.

En esta oportunidad surgió también la palabra gobernabilidad. Otra razón para la remuneración extraordinaria sería el peso de la carga que gravita sobre los magistrados constitucionales. En sus espaldas, dice el proponente, “...recae la responsabilidad de la gobernabilidad del país por los casos de gran impacto que deben votar" (Delgado, 19/03/2012: 16 A). Responsabilidad, gobernabilidad y represalias justificarían entonces el sobresueldo. Importante: en este razonamiento el problema de la ingobernabilidad no estaba en la Sala Constitucional, al respecto fue enfático el magistrado Jinesta en su intervención en la Corte, el día 19. Coincidía con sus colegas, llamativa es la facilidad con que se acude a la palabra gobernabilidad y se hace uso de ella. Se encontraba en el ambiente, al alcance de la mano.

El plan del plus salarial tardó más de un año en ser rechazado. No se sabe si alguien le advirtió al proponente de sus implicaciones para la reputación de la magistratura $y$ del Poder Judicial; al respecto no hay ningún indicio en la información disponible. La ingeniosa solución contra las presiones políticas y las muertes anunciadas iba en dirección de un ingreso más alto, en concordancia con el espíritu de los tiempos; al mismo tiempo condensaba una forma de entender los dilemas del Poder Judicial y la manera de lidiar con ellos.

\section{PUNTUACIONES}

Primero: Entre el 19 de junio del 2012 y los primeros días de enero de 2013, estuvo trabajando la denominada comisión presidencial de expertos en materia de gobernabilidad democrática, la llamada Comisión de Notables; su encargo, según ellos dirán, consistía en analizar los aspectos más urgentes en materia de gobernabilidad democrática y proponer cambios (Pacheco, 2013). La iniciativa tuvo como punto de partida el discurso de la presidenta Laura Chinchilla del 1 de mayo de 2012, en el cual ella advertía con preocupación que la ciudadanía daba muestras crecientes de escepticismo y frustración, así como había empezado a dudar de la democracia y de las intenciones de los gobernantes; las palabras de la Presidenta destacan un estado espiritual que se había traducido - a su criterio- en pérdida de legitimidad de las instituciones y en deterioro de la seguridad jurídica (Pacheco, 2013) ${ }^{19}$. Para entonces había evidencia empírica clara de un desgaste de las columnas de la estabilidad política.

En la parte del discurso presidencial reproducido al final del Informe de los Notables, la palabra gobernabilidad no aparece; la Presidenta llamó a reflexionar sobre las dificultades de la democracia. Sin embargo, el concepto de gobernabilidad, junto con todos los otros términos propios de este campo semántico, será el norte de trabajo de la comisión formada por la Casa Presidencial. Desde el primer párrafo del texto de los Notables, la palabra gobernabilidad queda en el centro, como lo sustantivo; la palabra democracia, como es usual en este uso, aparece como un adjetivo calificativo de lo sustancial.

Las propuestas para fortalecer la funcionalidad y calidad de la democracia, anunciadas en el título del documento de los Notables, desembocan en la afirmación de que los "muchos diagnósticos existentes convergen en reconocer que la gobernabilidad democrática es lo que está en crisis". De esos diagnósticos no hay información alguna; acto seguido, la atención es llevada hacia la reorganización del diseño institucional $y$ en ese terreno, la meta va a ser facilitar el ejercicio de la autoridad de los gobernantes, fomentar consensos políticos e impedir "el deseo de algunos de obstruir la democracia" (Pacheco, 2013: 9).

La palabra gobernabilidad lleva a las obstrucciones para el ejercicio de la autoridad de los gobernantes, a los "algunos" nombrados sin precisión, a la cuestión de un liderazgo bloqueado

19 Discurso presidencial sobre el Estado de la Nación del lero de mayo de 2012. 
$y$ de una voluntad mayoritaria neutralizada. La expresión sucinta y crítica del problema es un Poder Ejecutivo que con dificultad administra y mucho menos gobierna, así como a una Asamblea en la que no se pueden tomar decisiones de mayoría. La contraparte ( $y$ aparente causa dentro de este diagnóstico) sería el deslizamiento del poder hacia otros órganos y cuerpos que no son los responsables de gobernar. En este grupo, aparecen los medios de comunicación, los gremios y los grupos de presión, destacándose por la precisión con que se les nombra, "los órganos constitucionales o legales" (Pacheco, 2013: 11). La mención deja al Poder Judicial y a la Sala Constitucional del lado de quienes han ganado poder en detrimento del Ejecutivo y el Legislativo, $y$ en la lista de los que no son responsables de gobernar, junto a los medios, los gremios $y$ los grupos de presión. Se les reduce su peso conforme a la Constitución.

La Casa Presidencial escogió a la mayoría de los Notables con un criterio de afinidad política e ideológica. Cinco de los seis ocuparon cargos políticos diversos en las últimas dos décadas y otros tantos, habían avalado el Tratado de Libre Comercio con los Estados Unidos (Flórez-Estrada y Hernández, 2004) ${ }^{20}$; la mayor parte de ellos se estrenaron recién en este momento como expertos calificados en gobernabilidad democrática. A la vez, el Poder Ejecutivo coordinó la actuación de los diputados de la Asamblea Legislativa el 15 de noviembre: llamó y presionó gente, negoció para sumar votos y posiblemente, dispuso también guardar

20 De las seis personas que integraron la Comisión de Notables, la única persona que, hasta donde es de mi conocimiento, no ha pasado por cargos políticos es el Dr. Manrique Jiménez Meza. De él existe también una posición reflexiva sobre los perjuicios del TLC, expuesta antes del referéndum del año 2007. Al respecto: Algunas implicaciones jurídicas del TLC sobre la organización y actividad constitucional y administrativa del Estado Costarricense. El Dr. Jiménez también formó parte de la Comisión Especial sobre Roces Constitucionales del TLC, convocada por la Rectoría de la Universidad de Costa Rica. Al respecto: Roces constitucionales del Tratado de Libre Comercio entre República Dominicana, Centroamérica y Estados Unidos. Editorial Universidad de Costa Rica, 2007. silencio sobre las intenciones de fondo hasta el último minuto. Estuvo en los dos frentes, al igual que la perspectiva de la gobernabilidad. La teoría se puso en práctica y en ninguno de los dos lados, el enfoque de la gobernabilidad democrática dejó un espacio para una consideración de ese arco temático señalado por el Presidente de la Corte: "el clamor ciudadano por la justicia social", el colapso del Estado de bienestar, la fractura del pacto social y la ruptura con el sistema de división de poderes propio del Estado de Derecho. Delimitado el problema de la gobernabilidad a partir de los "múltiples diagnósticos existentes" no quedó una ventana para mirar en esa otra dirección.

En la presentación del documento de los Notables, los valores y la visión de la realidad, reconocidos "como el sustrato sobre el cual se levanta todo lo demás", quedan explícitamente fuera de consideración. Los Notables renuncian a ingresar en este delicado campo. No obstante, la organización del texto gira en torno al valor mayor suscrito: la gobernabilidad democrática. La renovación del diseño institucional del país conforme a un criterio de gobernabilidad aparece como la condición para la solución de los problemas materiales y sociales más agudos.

Mientras esto ocurre en el documento, en el frente legislativo, el motivo de la gobernabilidad ingresa como la razón de un veto político discrecional, sin palabras y a destiempo, en nombre de la mayoría, la posición que motiva los señalamientos del magistrado Arroyo $y$ de la magistrada Calzada sobre el uso de las herramientas de la democracia en contra de esta $y$ anteriormente, la denuncia de un ataque a la Constitución y al Estado de Derecho en nombre de la gobernabilidad. Los medios empleados para alcanzar la meta, mostraban dudas varias sobre la firmeza de las convicciones democráticas.

Vista en retrospectiva, en la sesión de la Corte del 19 de noviembre tuvo lugar una primera posición divergente contra el concepto $y$ la tesis vertebral del documento de los Notables. Se criticó el diagnóstico de base y se le señalaron sus puntos ciegos; varios de los magistrados y magistradas comentaron las derivas no democráticas del diagnóstico del país ingobernable. Mientras esto ocurría, el texto de los 
Notables, todavía en proceso, se concentraba en la crítica de los "poderes de veto" otorgado a "los poderes públicos, a los órganos constitucionales o legales". Aquí encuentra barreras a superar o a re-diseñar. Queda para la especulación si la alerta lanzada por Luis Paulino Mora sobre "...nuevas campañas de desprestigio de mayor debilitamiento contra los magistrados y la justicia..." tenía relación con lo que él pudiese suponer o saber ("información para mi creíble que esto se está tramando en este momento") sobre las amenazas para el Estado de Derecho en nombre de la gobernabilidad. Lo manifiesto en el documento de los Notables, visto como un conjunto, es que los órganos constitucionales $y$ legales tendrían que pasar por un reajuste; en lo concreto el informe limita a cuatro años el control de la constitucionalidad del procedimiento de aprobación legislativa y elimina la consulta facultativa de constitucionalidad por parte de los diputados, bajo el supuesto de que ello propicia la incursión de la Sala Constitucional en asuntos de la Asamblea Legislativa. Lo manifiesto en el texto del magistrado Mora es la mención explícita de la gobernabilidad "mal entendida" o manipulada, el señalamiento de una clase política sin un proyecto social de convivencia democrática y la advertencia sobre una posible deriva autoritaria.

Segundo: Palabras como gobernabilidad, ingobernabilidad, gobernación, gobernanza, agencia, actores y rendimientos de cuentas, ingresaron en el debate público en la última década del siglo pasado; por vía aditiva estos conceptos han ido conformando las columnas de una nueva lengua. Rápidamente, el novedoso lenguaje se extendió y oficializó, siendo adoptado por igual en el mundo académico y entre los operadores políticos de distinto grado y signo. Unos descubrieron allí una cantera de conceptos y una metodología para hacer diagnósticos, en un momento que las ciencias sociales estaban disminuidas desde la izquierda y acorraladas por la primacía de los economistas; otros encontraban además un arma práctica que abría diversas oportunidades de empleo al mismo tiempo que suavizaba las políticas de ajuste estructural de los años 80 , al darles carne social-institucional. No menos importante, es el lenguaje en que vienen las propuestas de cambio de las instituciones financieras internacionales que se autocriticaban por el unilateralismo económico de las políticas defendidas unos años atrás bajo el paraguas del Consenso de Washington.

Los muchos diagnósticos convergentes “... en reconocer que la gobernabilidad democrática es lo que está en crisis", apenas mencionados en el documento de los Notables, provienen de grupos y personas que, con diferencias de grado, piensan dentro de la nueva lengua $y$ participan de su lógica y su sensibilidad. Se escogió, si es que cabe la palabra, el diagnóstico más ofrecido. La profusa divulgación de la perspectiva de la crisis de gobernabilidad hizo que la gobernabilidad democrática se convirtiera en el principal reto a enfrentar, en Costa Rica, en el subcontinente y más allá. La tesis de la crisis de gobernabilidad se ha convertido en una roca firme sobre la cual trabajar; en su uso más divulgado no es esta una posición a debatir, ni una hipótesis sujeta a verificaciones o correcciones. Aquí no queda espacio, por ejemplo, para reflexionar si parte de lo calificado como síntomas de ingobernabilidad se podría leer como la expresión de una ciudadanía más atenta o eventualmente, como un experimento en marcha, en el cual se estaría ensayando la configuración de un sistema político que reposaría controles más extensos aunque también más difusos.

Conforme a este entendimiento de las cosas, el desarrollo supone y requiere de capacidades políticas y sociales; lo deseable es un sistema socio político estructurado, de tal manera que los actores se relacionan adecuadamente para tomar decisiones $y$ resolver conflictos conforme a reglas y procedimientos meridianamente estables, aunque con niveles desiguales de institucionalización. Pero como lo reconocen incluso, algunos especialistas con una carrera sólida en el tema, la difusión de esta lectura ha sido tan exitosa que ha terminado aguando la palabra gobernabilidad; esta es empleada de una manera desbordada e imprecisa, en todos los ámbitos se ha terminado descubriendo un problema de gobernabilidad 
(Prats i Catalá, 2001). Tal manejo laxo y sobreentendido, al mismo tiempo se puede ilustrar con el documento de los Notables; hecho el reconocimiento-diagnóstico de partida, el término se emplea sin mayor precaución. Aquí es donde se podrían empalmar las observaciones de Luis Paulino Mora sobre el concepto "mal entendido" $y$ los comentarios sobre su uso ligero, cuando no manipulado.

El universo conceptual en el cual se integra la palabra gobernabilidad empezó a tomar forma en América Latina entre los años 80-90, en el contexto de los procesos de transición (reales o nominales) hacia la democracia $y$ de los agudos desafíos sociales generados por la transición hacia las economías abiertas. Fue parte de un intento por defender la convivencia de la democracia con cambios estructurales que debían producir crecimiento $y$ desarrollo, pero que en el corto plazo traían consigo efectos sociales disgregadores. Implícito estaba el reconocimiento de que el crecimiento con estabilidad no depende solo de la acción de los gobiernos, sino de los recursos sociales y políticos para gestar y sostener redes de actores estratégicos, lo cual suponía a su vez que las políticas positivas $y$ deseables tales como, las privatizaciones y la apertura del mercado de capitales - herramientas indispensables de la estrategia económica propiciada - solo darían los frutos esperados si las instituciones existentes cumplían con un conjunto de requisitos de calidad y de funcionamiento. Esta última es la posición defendida por Francis Fukuyama, en la introducción de un extenso libro sobre las reformas del Estado en América Latina, publicado por el Banco Interamericano de Desarrollo en el año 2007; las políticas buenas, dice él aquí, pueden ser ( $y$ han sido) boicoteadas por deficiencias, bloqueos y cuellos de botella institucionales ${ }^{21}$.

La palabra institución es clave; esta conlleva a los aportes de la corriente de pensamiento económico y político conocida como

21 El desarrollo de esta idea se encuentra en: Lora, Eduardo (editor). El estado de las reformas de Estado en América Latina. Bogotá, Colombia: Mayol Ediciones, 2007. De particular interés es el prólogo del libro, escrito por Francis Fukuyama. el nuevo institucionalismo, en sus inicios estrechamente asociada con la obra de Douglass North $(1993)^{22}$. La perspectiva institucional introduce un elemento autocrítico; esta alude a los marcos formales e informales, materiales $y$ mentales que detienen, controlan, liberan o amplían la conducta individual. La institución remite a las reglas escritas pero también a las prácticas, los hábitos y las creencias que conviven e interactúan con las reglas oficiales o las atraviesan. El neo-institucionalismo regresa al hecho conocido de que las políticas no se implementan en desiertos sociales; las instituciones entendidas como portadoras de sentido, historia y sustancia social, canalizan, afectan y comprometen las políticas diseñadas, sin importar su bondad o su exactitud teórica. Las privatizaciones o las liberalizaciones financieras, no dieron los beneficios esperados porque han sido desvirtuadas por intermediarios y juegos de fuerzas; quienes formal o informalmente estaban mejor situados o mejor vinculados políticamente, las aprovecharon en su beneficio. Las viejas herencias institucionales las desfiguran y las convierten. Los resultados empírica y vivencialmente conocidos (pérdida de legitimidad política, regresiones autoritarias, desencanto ciudadano, extensión de la economía criminal, la corrupción y la aparición de nuevas cleptocracias, desigualdad y pobreza), serían, supuestamente, consecuencias imprevistas y no deseadas del estilo de cambio promovido.

Un reto consistiría entonces en entender con precisión las características del mundo institucional, atender sus dimensiones históricas, estructurales y coyunturales, con el fin de contar con herramientas para desarrollar un programa viable de reformas. Los estudios comparativos son bienvenidos. North recordará con insistencia que el capitalismo se desarrolló en los Estados Unidos y Europa sobre una base

22 Por su cercanía a nosotros y por brevedad puede verse el prólogo de Prats i Catalá titulado "Creencias, instituciones y democracia". Primer Informe Centroamericano de Gobernabilidad Jurídico-Institucional 2007-2008. Guatemala de La Asunción-San Salvador-Tegucigalpa-ManaguaSan José. Observatorio de la Democracia en Centroamérica-Instituto Centroamericano de Gobernabilidad, 2007-2008: 39-46. 
de transformaciones institucionales previas $y$ eso revirtió en su forma de despliegue: antes del despegue capitalista hubo reformas-revoluciones que aflojaron $y$ despejaron obstrucciones propias de formas de vida tradicionales (prebendas y usufructos, criterios corporativos $y$ patrimoniales). A su entender, esta sería una razón de peso por la cual las reglas informales y formales se aproximaron y se llenaron de contenidos más precisos.

Junto a la palabra institución, el concepto de reforma y sus sinónimos (ajuste, reajuste, rediseño y reingeniería) ocupan un lugar central. La innovación y la reforma quedan a la orden del día; los nuevos reformadores tienen la tarea de vencer las llamadas resistencias conservadoras; la palabra reforma adquiere con ello un sentido muy amplio, sirve para referirse a cualquier propuesta de mediano alcance que tenga como objetivo re-ordenar un campo de manera consistente con el norte del mercado, la apertura $y$ las privatizaciones.

El nuevo jalón modernizador requiere de instituciones ágiles y flexibles, de reglas predecibles y transparentes, de marcos en los cuales los actores puedan hacer cálculos que favorezcan y multipliquen la eficiencia, de evaluaciones de desempeño $y$ eficacia, de trabajo en redes $y$ de nuevas formas de coordinación entre los actores públicos y privados. Ante semejantes retos, no solo la disciplina económica está convocada.

Según la premisa de partida aceptada, el crecimiento económico por sí solo no genera la institucionalidad deseada, hay que construirla activamente. De conformidad con ello, en los años 90 empiezan a fluir recursos para consultorías $y$ asesorías en campos tan diversos como medio ambiente, eficacia legislativa, asuntos electorales, regímenes de pensiones y seguridad social, temas de género, corrupción, resolución de conflictos, derechos humanos y reforma judicial, entre otros. Muy cerca vienen las preocupaciones por las cuantificaciones, los índices y las matrices: para medir las libertades políticas y civiles, los rangos efectivos de responsabilidad política, la eficacia gubernamental, la estabilidad política, los grados de descentralización, la corrupción y la solidez del Estado de Derecho, entre otros. Los esfuerzos se concentran en la creación de mapas sobre los actores estratégicos, con sus complejidades (expectativas, reglas de interacción, reto $y$ desafíos). A la par ocurre un repunte de las técnicas de investigación, en particular, pero no exclusivamente, de los métodos cuantitativos.

Los nuevos retos requieren de una gama más amplia de profesionales, empezando por el Derecho y las Ciencias Sociales; ellos y ellas son también formados conceptual y técnicamente, llevados a un estilo de hacer preguntas, de pensar $y$ de pensarse. Esta es la ola que transporta $y$ es transportada por el lenguaje de gobernabilidad-gobernanza-gobernación.

El avance progresivo de la nueva lengua se puede seguir en los documentos del Programa de Naciones Unidas para el Desarrollo (pNuD), el Banco Mundial, el Banco Interamericano de Desarrollo y el Fondo Monetario Internacional. El concepto de gobernabilidad democrática estuvo inicialmente más cerca del pNud, mientras que el concepto de gobernanza, en sus diversas variantes, más próximo al Banco Mundial. Existen materiales para rastrear como la nueva lengua se precisa y ensambla, penetra en un gran número de institutos, organizaciones no gubernamentales, universidades y grupos profesionales. Algunos de estos hacen puente entre los organismos internacionales $y$ los gobiernos; otros, entre estos últimos y la llamada sociedad civil. Otros más se convierten en lugares de divulgación y enseñanza de la nueva lengua (Banco Interamericano de Desarrollo, 1990; Wilson, Rodríguez y Handberg, 2005). En poco más de una década y media, la nueva terminología se volverá de uso regular, cuando no obligatoria, para quienes laboral, política 0 mentalmente giran en las órbitas de estos organismos o en sus zonas de influencia, con la atención centrada en el re-ordenamiento institucional necesario para conseguir dinamismo económico y gobernabilidad democrática.

Tercero: Siempre se puede discutir si el paradigma de la gobernabilidad fue adecuadamente usado en el Informe de los Notables; personas simpatizantes de esta perspectiva podrían argumentar que las recomendaciones del documento no tienen sostén firme en un diagnóstico sistemático, como lo aconsejan muchos 
libros y se enseña actualmente en diversas universidades. El punto de partida de los Notables son los "múltiples diagnósticos existentes", pero esto deja un campo totalmente confuso - allí nos quieren dejar; por esta razón, el malestar. El presidente de la Corte Suprema de Justicia y varios de sus colegas dudaban de que el diagnóstico de la ingobernabilidad (o de crisis de gobernabilidad) fuese el adecuado, $y$ también que esos conceptos estuviesen siendo bien entendidos $y$ usados. Por ejemplo, los actos en el caso de la reelección del magistrado Cruz, no parecen dar cuenta de una preocupación por la gobernabilidad democrática, sino a lo sumo, por una gobernabilidad a secas, con visos autoritarios.

De manera parecida, se puede debatir si es suficiente llamar a una renovación del diseño institucional apelando a la convivencia democrática y la cohesión social, dejando por fuera la información de que ambas se han venido erosionando en los últimos veinte años (palabras clave: desigualdad, polarización social, fragmentación-desintegración del tejido social), valga decir, sin abordar de una manera frontal el tema de la democracia y su sostenibilidad, $y$ en un sentido más amplio, de las condiciones sociales de la democracia. Las y los entendidos en la materia recuerdan que la democracia no es una condición suficiente de la gobernabilidad democrática, pero que la segunda siempre presupone la primera. En condiciones en las cuales se acumulan las evidencias negativas y los escándalos se apilan diariamente, con el horizonte del país más desigual de los últimos 60 años, ¿tiene sentido plantearse el problema de la gobernabilidad democrática sin abordar de alguna manera la cuestión de la democracia social y de la convivencia democrática?, ¿¿se puede soslayar el tema si la gobernabilidad democrática estuviese pensada en función de una estrategia sólida de desarrollo humano y no solamente para permanecer en al ámbito de lo que Prats i Catalá - un reconocido experto en el tema- llama una democracia delegativa vaciada, cuyo peligro es acentuar más el deterioro de las instituciones políticas y sociales? (Prats i Catalá, 2001). Son preguntas abiertas; estas lanzan la inquietud de si — cuando menos en este caso — no se está simplemente ante términos usados como armas de lucha política, cuyo filo se emplea para abrir camino $y$ doblegar resistencias, más que para entender realmente. Existe una gran diferencia entre hablar una lengua, $y$ usar algunas de sus palabras para lograr un efecto específico.

En los últimos años, se ha producido una inmensa cantidad de diagnósticos, informes, balances y encuestas, con frecuencia con el apoyo directo o indirecto de organismos internacionales como los anteriormente citados. Se tiene un inmenso acervo de información sobre nosotros mismos, inexistente 35 años atrás. Las expectativas han sido altas: se quiere conocer con más precisión, producir trabajos comparativos para identificar buscar patrones de cambio y de estabilidad. La intención ha sido generar insumos para que los actores sociales y políticos puedan tomar decisiones más fundamentadas, poner temas en el debate, hacer contrastes entre la evidencia empírica $y$ lo que se dice $y$ hace. Notablemente, esta creciente acumulación de información no se ha traducido en la producción de lo que Norbert Lechner llamaba mapas interpretativos más adecuados para enfrentar nuestro presente; con harta frecuencia los insumos generados son leídos con la lente construida por el binomio gobernabilidad-ingobernabilidad. Al mismo tiempo, paradójicamente, los resultados políticos prácticos no han sido todo lo esperados por los promotores del cambio.

A pesar de tener los vientos a su favor, políticos e ideólogos locales del mercado se hacían las mismas preguntas que Fukuyama: “¿por qué el crecimiento económico, la disminución de la pobreza y la modernidad política no habían respondido con la celeridad que cabría esperar a la adopción de la democracia, la apertura comercial y las diversas políticas monetarias de precios $y$ de regulación más rigurosas y racionales, que eran ahora la norma en el continente?", se interrogaba el ex presidente Miguel Ángel Rodríguez, cuatro años después de terminar su presidencia, en medio del proceso judicial por su participación en el caso ice-Alcatel (Rodríguez, 2006).

El momento de éxito tiene un lado inexplicable. En la perspectiva de los neo-institucionalistas, se podría hablar de la inercia de lo 
viejo o desde Fukuyama, de las hibridaciones contraproducentes entre lo viejo y lo nuevo; pero de nuevo hay que pensar en lo que han traído un orden social y un estilo de desarrollo centrados en un mercado abierto controlado por grandes consorcios internacionales, en la manera y la dirección en que se han transformado $y$ trastocado el tejido social, en la aparición de múltiples intereses voraces y con mentalidad de corto plazo. También, muy cerca de todo esto, lo que sería imputable a la práctica de los re-ordenadores, a los caminos de cambio que han seguido $y$ a su responsabilidad en la producción activa del resultado lamentado.

En los albores del siglo xxi, el diagnóstico oficial-dominante decía que Costa Rica era un país estancado, varado, en el cual no pasaba nada; sin embargo, hacia atrás estaban los programas de ajuste estructural iniciados en los años 80 y sus resultados, nada despreciables en términos de la transformación social e institucional del país. Se estaba en el pináculo del bipartidismo, en el momento en que los dos partidos mayoritarios que favorecían la apertura tenían el control mayoritario de la Asamblea Legislativa. La pegajosa lectura del país estancado-frenado fue cultivada por los ideólogos y los promotores de la apertura económica, insatisfechos con lo conseguido, divulgándose en muchas distintas variantes, como puede verse en los informes sobre el Estado de la Nación de estos años. Para entonces, el tema de la gobernabilidad $y$ la ingobernabilidad había ingresado al debate político. Los términos aparecen en textos y discursos de Oscar Arias y varias polémicas en la prensa, a mediados de los años 90, durante el gobierno de Figueres Olsen. Los retos y problemas se empezaron entonces a ver en el nuevo lenguaje. Cuando menos uno de los Notables de 2012, tomó parte en estas discusiones (Méndez, 03/05/1995: 4) ${ }^{23}$. Sin embargo, no

23 En mayo de 1995, el entonces diputado Constantino Urcuyo, uno de los Notables, le reprochó al Presidente Figueres Olsen manejar un concepto de ingobernabilidad en el cual no había propósito de enmienda respecto a las veleidades autoritarias y el irrespeto a los Poderes del Estado. En su informe del 1 de mayo, el Presidente Figueres había mencionado el peligro de que el país se volviese ingobernable como resultado del era todavía la conceptualización dominante y en buena medida estaba supeditada a las luchas entre los dos partidos políticos mayoritarios. No obstante, con el debate sobre el Tratado de Libre Comercio con los Estados Unidos (2007) hay un giro. La lectura oficial, tanto entre los políticos como entre muchos tecnócratas, pondrá el acento en el país ingobernable, imposibilitado por ello de aprovechar las oportunidades existentes para alcanzar el desarrollo. Las raíces nombradas del problema serían conocidas: por un lado, resistencias institucionales $y$ por otro, la ausencia de un liderazgo firme que termine de romper con lo viejo y marque nuevos rumbos. Una parte desapercibida en el uso ligero de esta nueva terminología es que la llamada situación de ingobernabilidad había sido generada también por los nuevos reformadores y no solo, como ellos lo querían presentar, por los obstáculos institucionales con los cuales tropezaban o por los llamados problemas de liderazgo, en los cuales se insiste con intenciones electorales precisas.

A principios de 2012, el ex vicepresidente y ex ministro de la República, Kevin Casas Zamora, abogado y politólogo, expuso su convicción de que Costa Rica se había transformado en un país ingobernable, sin esperanza alguna de llegar a ser el primer país desarrollado de América Latina. La meta de convertirnos en el primer país desarrollado del subcontinente, la había vuelto a proponer Oscar Árias Sánchez en el año 2005, cuando se postuló a la presidencia por segunda vez: el objetivo era alcanzable, se decía entonces, solo faltaba voluntad política $y$ liderazgo para crear las condiciones $y$ dar el gran paso (Arias, 2005: 296 y ss). Casas participó activamente de este anhelo. Pero siete

debilitamiento de las instituciones del Estado. Urcuyo, según trascendió en la prensa, relacionaba la ingobernabilidad con una conducción errática y desacertada del país por parte del Poder Ejecutivo: "Gobernabilidad son logros, resultados, eficiencia y legitimidad", decía el diputado. Al mismo tiempo, le reprochaba al Presidente el no reconocimiento de los errores cometidos, entre los cuales se contarían, la violación de la Constitución Política, enfrentamientos con la Corte Suprema de Justicia, detenciones ilegales, violación de derechos humanos y represión de los trabajadores. 
años después de puesto tan ambicioso norte, constataba Casas, se encontraba con un cuadro desalentador: de los seis indicadores del gobernabilidad empleados por el Banco Mundial (voz y rendición de cuentas, estabilidad política y ausencia de violencia, efectividad del Gobierno, calidad de la regulación, vigencia del Estado de Derecho y control de la corrupción), el país había retrocedido en cinco de ellos entre el 2000 y el 2010, algo que, subraya él, no se podía decir de ningún otro país centroamericano. La causa era un sistema político incapaz de articular intereses, construir consensos, tomar decisiones y ejecutarlas, palabras más o menos, el mismo diagnóstico de los Notables. Concluía Casas: "Hoy tenemos un Poder Ejecutivo que no Ejecuta, un poder Legislativo que no legisla $y$ un Poder Judicial que los sustituye a ambos. Costa Rica ya no es gobernable" (10/01/2012: 29 A). El país sufría de "esclerosis", se dice en el réquiem de Casas; el sueño del país desarrollado se había mostrado como una vana ilusión; un síntoma y causa del padecimiento, entre varios otros, era un Sistema Judicial que sustituía a los otros dos poderes de la República. Otra vez, el Poder Judicial queda en la columna negativa; posición en la que estaba mucho antes de que se redactara el Informe de los Notables.

Las palabras indicativas de la enfermedad reaparecerán un año más tarde en el artículo en el cual la Presidenta de la República anunciaba $y$ comentaba el texto de los Notables: también para ella habíamos degenerado "en un Estado esclerótico y atrofiado" (Chinchilla, 18/01/2013: 31A). La misma escuela, en un tramo cercano de sus respectivas carreras, ella y Casas habían sido compañeros políticos próximos.

A la luz de este tipo de apreciaciones, hechos como los ocurridos en noviembre de 2012, en la Asamblea Legislativa podían adquirir incluso un cariz heroico, presentarse como acciones urgentes, incluso desesperadas, para reanimar-sincronizar las instituciones del país esclerótico-desahuciado, aunque hubiese quienes verbalizaban la tarea por delante de una manera más prosaica, pero no inexacta, reclamando un clima institucional proclive a los negocios, justo cuando los negocios fraudulentos, desde el Estado o en todo caso desde posiciones de poder, atraían cada vez más la atención de la ciudadanía. Los nuevos reformadores o cuando menos algunos de ellos, podían pensarse como revolucionarios que alcanzaban a otear un futuro prometedor. Tenían, conforme a las imágenes empleadas por el ex presidente Arias Sánchez, la visión del águila.

Pero soltar el lastre de lo tradicional tiene costos; incluso se puede entrar en contradicción con los postulados reivindicados como guías de la acción (legitimidad, consenso, confianza y cohesión), paradójicamente, en aras de ellos mismos. Casas se convertirá en un conspicuo ejemplo de las trampas trágicas, en las cuales podían enredarse los re-ordenadores cuando actuaban sobre terreno. Él reunía todos los méritos intelectuales y profesionales para formar parte del grupo de los Notables, pero consideraciones de conveniencia política impedían siquiera mencionar su nombre. Era, todavía en este momento, un paria político. Sus denodados esfuerzos desde la vicepresidencia de la República por vencer el movimiento de resistencia a la firma del Tratado de Libre Comercio con los Estados Unidos, en la misma trinchera que la mayoría de los Notables, lo llevó a idear y propiciar una política de amenazas, intimidación y de manipulación con el fin de sumar votos en el referéndum convocado para decidir el tratado. Las presiones y los chantajes ideados se integraron a una estrategia, en la cual participó la prensa, las cámaras empresariales y los partidos políticos aperturistas. En el 2007, estuvo en el ambiente el argumento del número y la mayoría. Los resultados de las elecciones del año 2006 legitimaban los pasos desagradables que había que dar para materializar "la voluntad popular". Convenientemente, se pasaba por alto que en esas últimas elecciones, la diferencia entre el vencedor con el contrincante próximo, adversario del trc, fue apenas de dieciocho mil votos, un $1 \%$ del electorado.

A causa del escándalo político ocasionado por el llamado Memorando Casas-Sánchez, en setiembre de 2007, el vicepresidente y ministro Casas Zamora se vio obligado a presentar su renuncia. Cayó y lo dejaron caer. Relevante para nuestros efectos es que la estrategia de 
miedo se ideó como un paso desesperado ya que, según quienes la propusieron, los "recientes escándalos" habían minado la confianza en el estamento político y los "niveles de gobernabilidad del gobierno eran ya muy bajos $y$ probablemente insuficientes para conferir legitimidad a un proyecto tan controversial. En este momento - se lee en el Memorandonadie le cree una palabra al gobierno ni a los políticos y por ello sería una locura delegarles la función de defender el tratado..." (Casas y Sánchez, 29/07/2007).

En este documento, pensado para la lectura del presidente Arias Sánchez y sus próximos, el problema de la gobernabilidad es directamente relacionado con una clase política desprestigiada; los "recientes escándalos" mencionados son los actos de corrupción en los cuales han estado implicados las cúpulas del estamento político. Esta dimensión de la llamada "crisis de gobernabilidad" desaparecerá totalmente en el Informe de los Notables. No es la única. En otro tramo del Memorando, en el apartado sobre los cuatro tipos de miedo que debían fomentarse, la palabra ingobernabilidad designa uno de los temores específicos que debían ser alentados para provocar un voto a favor del tratado. Dice: "Mucha gente simplemente no ha hecho la conexión de que un triunfo del no en el referéndum, dejaría al Gobierno en una posición precaria, con su efectividad totalmente reducida, $y$ al país en una situación de ingobernabilidad. Esa conexión hay que inducirla. Este es un argumento que puede que solo funcione para ciertos sectores, pero puede ser muy efectivo sembrando la duda" (Casas y Sánchez, 29/07/2007). Dos veces consecutivamente se repite la palabra sembrar. Se trata de plantar miedos y cosechar sus frutos, de manipular con un propósito específico. La palabra gobernabilidad, en esta acepción, significa tan solo conducir la conducta de la población, gobernar sobre el comportamiento de la gente, sin resistencias. Lo contrario sería ingobernabilidad. Este uso del término ingobernabilidad no desapareció con la renuncia de Casas; perdurará como una gran tentación y la gran meta. Los politólogos que redactaron el Memorando sabían lo que decían y lo que hacían.
Dos años antes de encontrarse en la situación que truncó una prometedora y acelerada carrera política, el consultor del Programa de Naciones Unidas para el Desarrollo (PNUD), Casas Zamora, aparecía como la persona que coordinó e inspiró un voluminoso y detallado trabajo publicado con el nombre "Venciendo el temor". El texto pretendía contribuir a la expansión de las libertades de las personas en sus diferentes expresiones, propiciar una convivencia respetuosa y una cultura de paz. Este material era considerado como otro aporte más para la conformación del país gobernable, con el auspicio de una institución identificada con la perspectiva de la gobernabilidad democrática (PNUD, 2006) ${ }^{24}$. La teoría y la práctica mostraron esta vez sus contradicciones con una diferencia de tiempo.

La forma de practicar la política de cambio $y$ gobernabilidad puso un grano de arena, uno grande, en la configuración del supuesto país ingobernable, al cual se le cantaba réquiem en el 2012. El Memorando es uno más de esos hechos que acumulativamente, van a golpear negativamente los índices del Banco Mundial, la evidencia empírica usada para apuntalar la tesis de la ingobernabilidad. A su vez, el Memorando se inscribe en el ascenso $y$ quiebra del bipartidismo, hecho que se debe relacionar con las reformas aperturistas y las nuevas dimensiones que adquieren las prácticas corruptas. Sobre esto, caen los intentos verticales $y$ autoritarios por avanzar en el camino de la gran reforma anhelada. Varias veces se menciona en el Memorando, como algo a evitar a toda costa, la derrota de la reforma a la ley de energía y comunicaciones en el año 2000. Fue entonces cuando se agudizó el declive del prestigio de la

24 Venciendo el temor. (In) seguridad ciudadana $y$ desarrollo humano en Costa Rica. Informe Nacional de Desarrollo Humano 2005. Programa de Naciones Unidas para el Desarrollo. San José. 2006. En el año 2004, Casas escribió una ponencia con el título: "Violencia, inseguridad ciudadana $y$ desarrollo humano en Costa Rica. Una aproximación conceptual y democrática". En: Memoria Taller de Respuestas democráticas al problema de la violencia. San José. Fundación para la Paz y la Democracia - FUNPADEM. Octubre. 2004. 
clase política, antes incluso de los procesos contra los ex presidentes.

Otros muchos sucesos, directa o indirectamente relacionados con la aprobación del TLc, astillaron aún más la confianza institucional y profundizaron las fracturas que venían tomando forma. A finales de 2012, el Tribunal Supremo de Elecciones declaraba que no se le podían quitar las credenciales a legisladores acusados de cometer faltas de probidad $y$ honradez; la razón del pronunciamiento era la situación de un diputado contra el cual la Fiscalía General había abierto una indagatoria. Tres años antes, la misma Sala Constitucional rechazó la declaratoria de inconstitucionalidad de cuatro artículos de la Ley contra la Corrupción y el Enriquecimiento en la Función Pública propuesta por el diputado Fernando Sánchez, co-autor, junto con Casas, del Memorando. El entonces diputado trataba de evadir con ello una posible expulsión de la Asamblea Legislativa. Su iniciativa no prosperó en la Sala Constitucional, pero en esta oportunidad, la Sala le pidió a la Asamblea Legislativa que se diera un marco para regular este tipo de faltas; en su ausencia las y los congresistas podían quedar impunes.

Pasados los años, el reglamento solicitado seguía sin existir, carecía de "ambiente político", se decía; un sector mayoritario de las y los diputados rechazó el pedido de la Sala Constitucional en la Asamblea Legislativa apelando a la independencia de poderes y la no intromisión de uno en otro. Quedó así un vacío legal del cual se benefició el diputado Sánchez, primo del presidente de la República en ejercicio, otra vez en detrimento del diezmado prestigio de la Asamblea Legislativa. Este podría ser otro ejemplo de un Poder Legislativo que no tomaba decisiones y contribuía a la ingobernabilidad $y$ por lo mismo, una razón más para tomar con precaución el argumento de la ingobernabilidad tal como fue usado en noviembre de 2012, en la misma Asamblea Legislativa.

La colusión de la institucionalidad formal-informal trabajó a favor del diputado que trató de debilitar la Ley contra la corrupción y el enriquecimiento ilícito en la función pública: en el siguiente gobierno el ex diputado Sánchez fue designado embajador ante el Vaticano, una particular manera de beneficiarlo y limpiarlo al mismo tiempo, con otro costo político que posiblemente habría que sumarlo, también, a la cuenta de la ingobernabilidad.

Luego, las dudas sobre el uso del concepto gobernabilidad que saltaron en la sesión de la Corte Plena del día 19 de noviembre eran producto del momento, pero también de otras acciones previas ( $y$ no acciones) ejecutadas en su nombre. De todo ello salen algunas de las sombras, no necesariamente las más densas, que alcanzan al texto de los Notables, redactado en forma paralela a los sucesos ocurridos en la Asamblea Legislativa en noviembre de 2012.

Nuevamente, existe otro lado que no debe perderse de vista. Una extensa fila de prácticas posibles de situar polémicamente entre los obstáculos de la gobernabilidad, se relacionan también con los cambios de corto $y$ largo plazo impulsados en el Poder Judicial. Desde los años 80 y con más decisión desde la última década del siglo anterior, hubo un conjunto de iniciativas encaminadas a formar una judicatura con mayor autonomía e independencia, más capacitada para hacer su trabajo, y con mejores recursos materiales y técnicos a su disposición. Como en toda la América Latina, en Costa Rica, el Gobierno y los organismos financieros internacionales venían canalizando una importante cantidad de recursos hacia la modernización del Poder Judicial, bajo el supuesto de que una economía dinámica y una vida democrática robusta requerían de reglas claras y de una judicatura expedita, no torcida o manipulada políticamente. Un objetivo importante, como se repetirá en muchos diagnósticos de organismos internacionales, era romper los estrechos lazos entre la política y el aparato judicial, una situación supuestamente propia de las sociedades no modernas.

Así, aunque los resultados son dispares, lo que se observa en esta situación, es que casos complejos tanto por las personas como por los intereses involucrados, empezaron a llegar a los tribunales comunes, donde quedaron a cargo de cortes compuestas por juezas y jueces para los cuales su trabajo consistía en impartir justicia, sin atender las calidades sociales y políticas 
de los acusados. Este es el contexto en el cual se sitúan las preocupaciones de la Presidencia sobre la pérdida de legitimidad de las instituciones y el deterioro de la seguridad jurídica, en el mensaje del 1 de mayo de 2012. El caso de la minera Crucitas aparece aquí, sin ser nombrada explícitamente. En perspectiva, la Presidenta repetía un estribillo frecuente en los discursos de Óscar Arias Sánchez desde principios del nuevo siglo, cuando menos, posiblemente anclado en los tropiezos anteriores del proyecto aperturista ( $\mathrm{La}$ ingobernabilidad y la inseguridad jurídica. En: <http://www.nacion.com/ opinion/foros/ingobernabilidady-seguridad-juridica_0_1213478672.html>).

En años recientes, una parte de los cambios dirigidos a mejorar la calidad $y$ la transparencia de los servicios públicos, incluyendo al Poder Judicial, han estado pensados en función de reducir "...los factores más problemáticos para hacer negocios". Esta expresión aparece al principio $y$ al final de un artículo escrito por el magistrado Rolando Vega Robert y el decano del INCAE Business School, en el cual se identifica la ineficiencia de la burocracia gubernamental como el principal factor que dificulta el hacer negocios (business) en Costa Rica; la fuente de la información era el Global Competitiveness Report del año 2009-2010 (Zúñiga $y$ Vega, s.f. $)^{25}$. Esta otra preocupación por las obstrucciones de los negocios se sitúa en el marco de las propuestas de modernización del Sector Público, se orienta hacia los resultados $y$ la eficiencia mediante una mejor gestión del presupuesto público.

La Corte Suprema aprobó en el año 2005, el programa de Gestión Integral de Calidad y Acreditación con la meta de propiciar un marco normativo para regularizar y estandarizar la calidad y eficiencia de los servicios prestados en los despachos judiciales, así como

25 En el documento "Sistema de gestión integral para la justicia: calidad al servicio del ciudadano", se inicia y finaliza con el tema de los factores problemáticos para hacer negocios. En la conclusión se lee: Los resultados alcanzados a la fecha lucen promisorios y van en la línea de eliminar de la lista de factores más problemáticos para hacer negocios en Centro América precisamente, la ineficiencia de la burocracia gubernamental. establecer criterios para decisiones presupuestarias conforme a evaluaciones previas de desempeño. Se asume una perspectiva gerencial, la cual tuvo consecuencias en el 2008, cuando con el motivo de la gerencia, la Corte aprobó un aumento de salarios que la beneficiaba. La Gestión Integral se une a su vez en un conjunto más amplio de iniciativas novedosas, entre las cuales se encuentran las acciones dirigidas al fortalecimiento de la administración, la renovación y la modernización de la infraestructura física, así como, la formación de capacidades humanas en un sentido más extenso. En esta fila viene también la Resolución Alternativa de Conflictos, una constante en la agenda de los organismos financieros internacionales, pensada como una forma expedita de resolver disputas diversas, muy especialmente las que podían surgir en el escenario de las transacciones económicas en el mundo global.

Se habla entonces de cambios (y no cambios) desiguales $y$ de sus consecuencias. Se debe pensar en los complejos efectos de las instituciones que no quedan en el centro de la consideración teórica y práctica de los re-odernadores, en las dificultades de la nueva lengua para enfocar $y$ dar cuenta de aquellos nudos conflictivos para los que no tiene palabras adecuadas, porque los relega o deja de lado, así como en la calidad e intensidad de los conflictos que surgen en razón de lo que ella propicia o alienta, unas veces de manera consecuente y otras tantas de manera no deseada. Además, están las viejas prácticas y mentalidades transportadas corriente abajo, como lo temían North $y$ los neo-institucionalistas, reapareciendo (con variantes o sin ellas) entre los abanderados de lo nuevo, embonándose de distintas maneras con los fines declarados, tiñéndolos. Lo sabido: los medios empleados dicen algo sustancial de los fines realmente buscados, más allá de como estos últimos se formulan en el papel.

De la convergencia de estos impulsos y resultados sale combustible para el malestar y la protesta, para la suspicacia, la desafección $y$ la litigiosidad, para las resistencias activas $y$ pasivas, también para los intentos de abrogar los marcos legales instituidos, eliminar controles, suprimir o reducir el rendimiento de cuentas. El 
Poder Judicial queda presionado, tanto desde el lado de quienes dicen actuar en nombre de una quiropraxis social igualada al desarrollo $y$ el progreso, como del lado de quienes contabilizan las pérdidas en el nuevo tejido social que toma forma y las tratan de minimizar. De esta incómoda posición salen las críticas al poder excesivo ( $y$ no sincronizado) concentrado en el Poder Judicial, a su falta de alineamiento, $y$ con ello, los intentos de influenciar y dirigir su cúpula con propósitos diversos, algunos muy específicos y de corto plazo. A la vez, brotan las críticas a una magistratura permisiva, tolerante o lenta, particularmente cuando se trata de los asuntos de interés de quienes están en posiciones de poder; en este caso, se advierte un excedente de alineamiento o sincronización, una con-fusión en detrimento del sistema de división de poderes. Lo que desde una esquina puede ser apreciado como un ejercicio de control y de aplicación de la ley, desde otra puede ser considerado un obstáculo, una injerencia en otro poder o la señal de una conjura de los políticos.

Cuarto: Los bandos que se enfrentaron en la Asamblea Legislativa en noviembre de 2012, evocaron los años 40 para resaltar una crisis institucional de dimensiones mayores. Unos $y$ otros se complementaron mostrando una situación en la cual las fronteras entre los tres poderes de la República aparecen desfiguradas, con la consiguiente conformación de zonas indefinidas, no reguladas o reguladas de manera arbitraria. Si las instituciones con legitimidad aportan barandas materiales y simbólicas para encausar las acciones, lo observado se aproxima más a la imagen de un campo abierto y resbaladizo, en el cual no hay asideros, donde las señales faltan o se están cambiando, son confusas o (intencionalmente) equívocas. Sobre este suelo se dan pasos calculados con resultados inciertos, giros imprevistos, desatenciones y deslices con consecuencias.

La votación del 15 de noviembre ocurrió entre un conjunto de movimientos en los que parece entremezclarse la decisión de sacar provecho de márgenes imprecisos, con la lentitud o la indecisión por motivos confusos. La Corte agregó sus gotas de aceite en el terreno ya de por si resbaladizo. En la nota en la cual esta le indicaba a la Asamblea el próximo vencimiento del plazo del magistrado Cruz y su intención de reelegirse, aparece que el trámite debía de hacerse al amparo del artículo 163 de la Constitución Política. Aparentemente, el comunicado se hizo sobre un machote de oficio empleado tanto para elecciones como para reelecciones, del cual se le envió copia al magistrado Cruz y al Departamento de Personal de la Sala Constitucional, sin que nadie advirtiera las complicaciones que podrían surgir. No era la primera vez que algo así sucedía. La misma referencia al artículo 163 aparece en las comunicaciones sobre otras reelecciones a efectuarse para estos mismos días; un ejemplo es la del magistrado Orlando Aguirre de la Sala Segunda, conocido por el Plenario el 30 de octubre de 2012. Aguirre fue reelecto por cuarta vez, el 10 de diciembre de dicho año.

El desliz de la Corte respecto al art. 163, trasciende en el contexto de las críticas del Ejecutivo y el Legislativo a la Sala Constitucional y al Poder Judicial. La nota-machote sirvió para que la presidencia de la Asamblea Legislativa argumentara que la ruta seguida hasta el 15 de noviembre, había sido la indicada desde el Poder Judicial, asimismo para que los adversarios de la reelección defendieran la legitimidad de lo actuado, poniendo la responsabilidad en la impericia de la presidencia de la Asamblea, en la Corte y en la Sala Constitucional, la última por haber dejado pasar antes otras reelecciones ocurridas después de haber vencido el plazo por el que estaba nombrada la persona postulante.

La desatención en el documento de la Corte adquiere relevancia en el marco de una disputa por el prestigio. Una advertencia sobre "nuevas campañas de desprestigio contra el Poder Judicial" aparece en la sesión de Corte Plena del 19 de noviembre, en boca de su Presidente. A su vez, la cuestión del prestigio resulta comprensible al observar la distancia entre el grado de confianza que tiene la población, por un lado, hacia los diputados y los partidos políticos, $y$ por otro, hacia los Tribunales de Justicia. De los tres poderes, el 
Judicial es el que había sido mejor evaluado en la última década ${ }^{26}$.

En los últimos años, las críticas a la Corte y a la Sala Constitucional se han incrementado en razón de motivos claramente políticos. Las razones conforman un arco variado, el cual se extiende desde la pérdida de independencia de la judicatura y los usos indebidos de los cargos de magistrados, hasta temas relacionados con los privilegios de la Corte y el Poder Judicial, pasando por la delicada situación de una judicatura cada vez más exigida a causa de la conflictividad social y las demandas de la población, este último aspecto correlacionado con el importante espacio para hacer valer los derechos fundamentales, expuesto con la creación de la Sala Constitucional y con los cambios modernizadores ocurridos en el Poder Judicial desde finales del siglo anterior. Asimismo, aparece el tópico de la cantidad y calidad de los recursos humanos y materiales para enfrentar retos crecientes, aspecto que frecuentemente se detiene en las limitaciones $y$ deficiencias formativas de los $y$ las integrantes de la judicatura. Por diferentes vías, tales preocupaciones se entremezclan con la polémica existente entre quienes dentro $y$ fuera del Poder Judicial abogan por una justicia con garantías fundamentales y quienes están por una justicia de corte represivo. Cada una de estas dos posiciones sintetiza una forma de

Entre 2003 y 2011, en una escala de 1 a 10, la confianza de la población en los diputados y diputadas llegó a un máximo de 4, 20 y a un 4, 31 en los partidos políticos. En ese mismo lapso, los Tribunales de Justicia recibieron un máximo de 6,49 y un mínimo de 5,89. El puntaje más alto fue en el 2003. De allí había descendido a 5,89 en el 2007 y a 6,34 en el 2011. Se agradece al investigador Marco Fournier esta información, la cual corresponde a un proyecto de investigación realizado en el Instituto de Investigaciones Sociales y el Centro de Investigaciones Políticas, ambos de la Universidad de Costa Rica. Otras fuentes confirman esta tendencia: según el Barómetro de las Américas, para el 2012, la confianza en el Poder Judicial y el Sistema de Justicia era de 47,2 y 46,8 respectivamente, mientras que la confianza en el parlamento (en nuestro caso Asamblea Legislativa) era de 37, 9; en la presidencia de 42,7 y en los partidos políticos de 31,5 . En los años para los cuales se tienen datos (2004, 2006, 2008, 2010), la diferencia entre el Poder Judicial, el parlamento y los partidos políticos se mantiene (Alfaro y Seligson, 2012: 30). entender el lugar y las tareas del Poder Judicial en la sociedad costarricense que ha venido cobrando forma en las últimas décadas.

Esta última discusión conduce a la pregunta de si a una sociedad con tensiones sociales y políticas crecientes corresponde un derecho feroz, convertido en su principal trinchera de defensa o si por el contrario, el lugar del Poder Judicial debe estar en consonancia con la tarea de preservar un orden social capaz de garantizarle a la mayoría de la población niveles de bienestar básicos, con respeto de sus derechos fundamentales. La primera opción se aproxima a una sociedad tensada desde el lado represivo del Estado, bajo el supuesto de que el delito es un asunto personal sin relación con las condiciones sociales existentes $y$ la segunda, a un Estado de Derecho, el cual, en primera instancia, se debería sostener desde la consistencia del tejido social mismo y por lo tanto, desde el arraigo social de sus instituciones.

El legislador que se pronunció por una magistratura sincronizada-alineada denunció la cúpula del Poder Judicial por haber ejercido el poder a su disposición en beneficio propio. Sus argumentos se apoyaban en un conjunto de situaciones presentes en los medios. En el 2008, la Corte acordó un incremento salarial para 46 altos funcionarios del Poder Judicial, incluidos los mismos magistrados (fue cuando aparecieron los argumentos gerenciales). A ello se sumó, en el 2010, la decisión de la Sala Constitucional de romper el tope que fijaba las pensiones de la cúpula del Poder Judicial y en el 2011, la decisión de la Corte de elevar la cesantía de 8 a 12 años. Cuando esto se anuncia, estaba en debate el plan fiscal y el incremento de la carga impositiva; la decisión de la Corte aparece en este contexto como un privilegio autoasignado que además, podía comprometer el fondo de pensiones del Poder Judicial. Estos motivos se amarrarán con las críticas a la Sala Constitucional por haberse convertido en un cuerpo por encima de la Asamblea Legislativa y también con las publicaciones en la prensa sobre la persistencia en sus puestos de un grupo de magistrados $y$ magistradas en edad de pensionarse, obstruyendo el ascenso de gente nueva y nuevas ideas. La conclusión del diputado era: "son 
necesarias reformas en el Poder Judicial para que sea más eficiente, más transparente y que los privilegios sean la excepción y no la regla" (Rivera, 03/04/2013); es decir, otra vez la idea de una institución urgida de un rediseño. Los cambios por jubilación venían a ser un posible camino para aproximarse a lo deseado.

Señalamientos como estos tocan fibras sensibles dentro y fuera del Poder Judicial; existen malestares y resentimientos de distinta naturaleza a los cuales pueden adherirse. Un objetivo era sacar ventajas de las insatisfacciones presentes, reducir las diferencias de prestigio con la Asamblea Legislativa y aumentar sus márgenes de maniobra de la corriente pro gobernabilidad.

La lucha en el campo del prestigio estaba decantada a mediados de 2012, seguramente desde antes. Con un extenso artículo, el presidente de la Corte buscó intervenir en esta resaltando que el Poder Judicial tenía una aceptación de un 59,7\% entre la población, en un momento en el cual existía un descontento mundial con las cortes y los poderes judiciales. La media latinoamericana de confianza no superaba el $40 \%$ y recientemente había alcanzado su nivel más bajo en los Estados Unidos, con un $52 \%$. No se estaba entonces tan mal. A su entender, el malestar con la justicia debía integrarse en un descontento con la democracia como sistema, por no poder garantizar niveles de bienestar básico a la mayoría de la población; ello revertía en un crecimiento continúo de las demandas que desembocaban en el Poder Judicial a causa de la judicialización de los conflictos políticos y sociales. No era una respuesta inexacta, pero tampoco era suficiente (Mora, 20/05/2012: 29A).

La encuesta para medir la confianza del Poder Judicial del primer semestre de 2012, mostraba que la población en más de un $80 \%$, estaba dispuesta a acudir a los tribunales para resolver querellas patrimoniales, familiares 0 laborales, lo cual, en una lectura positiva, podía tomarse como un índice de madurez en el manejo de conflictos. Pero al mismo tiempo, entre las personas consultadas, la confianza en la igualdad, eficiencia, honestidad $y$ honradez del aparato de justicia oscilaba entre el $37 \%$ y el
39\%. El promedio de estos dos subíndices daba un índice de confianza de 59,7\%, el cual — siendo comparativamente positivo- ocultaba un grado importante de incertidumbre respecto a una justicia igualitaria, eficiente $y$ honesta. La diferencia de los subíndices invita a pensar en una relación funcional-pragmática con la institución judicial, pero con una convicción debilitada (Poder Judicial, 2012).

Ahora bien, la lectura sobre la confianza en el Poder Judicial cambia cuando la información se pone en el tiempo. Según otras fuentes, la confianza en el Sistema de Justicia y la Corte había decrecido entre el año 2004 y el 2012. La confianza en el había pasado de 61,5\% (2004), $52 \%$ (2008) y 46,8\% (2012). Los valores para la Corte Suprema eran de 61,9\% (2004), 55,2\% (2008) y 47,2\% (2012) (Alfaro-Redondo, 2012).

Durante un encuentro académico realizado en la Universidad de Costa Rica a finales del año 2011, una respetada jueza criticó desde dentro, a un Poder Judicial aquejado de vicios que comprometían la legitimidad de la justicia impartida. Los dos subtítulos del texto destacan una situación de decadencia y vicios estructurales. Los indicios, argumentaba ella, sugieren un uso de las posiciones magisteriales para favorecer intereses político-personales-económicos (reelección presidencial, magistrados suplentes que utilizan el cargo para alentar causas específicas e intereses propios, rumores de cómo podían votar los magistrados de la Sala III de la Corte y el tribunal de apelación, al cual se elevó la causa contra el ex presidente Calderón Fournier) y la existencia de mecanismos institucionales turbios para filtrar el acceso a las posiciones en las cuales se toman decisiones estratégicas (de lo cual sería un ejemplo, la ausencia durante 17 años, hasta recién en el 2012, de criterios para conformar la listas de magistrados suplentes de las cuales debía escoger la Asamblea Legislativa), a todo lo cual se deben sumar las particularidades del proceso político de selección de las y los integrantes de la magistratura en la Asamblea Legislativa (Chinchilla, R., 31/01/2012: 2-3).

Además, la jueza mencionaba el aumento de salarios de los magistrados por funciones de alta gerencia en el 2008, a lo que se podría 
agregar (ella no lo hace) el frustrado sobresueldo por riesgo político, la eliminación del tope de las pensiones para los magistrados y el incremento del pago de la cesantía para quienes trabajan en el Poder Judicial. A su criterio, los actos discrecionales de la cúpula judicial (viajes, el uso efectivo del tiempo, combustible, choferes y criterios para las designaciones que les competen) carecían de motivaciones claras. Nuevamente, en el 2012, hubo una fuerte discusión dentro de la Corte Plena a propósito de la utilidad de los viajes al extranjero que no la mostró desde su mejor lado; el móvil de fondo parece haber sido una lucha de poder que tomaba como motivo un punto vulnerable.

Este artículo contiene un reclamo por la ausencia de "...decisiones en clave institucional $y$ de largo plazo" $y$ "...el predominio de visiones personales y cortoplacistas, sin ponderar el daño social que se le efectúa a un Poder esencial en la vida democrática" (Chinchilla, R., 31/01/2012: 2-3). Lo resentido es la debilidad de un pensar y un actuar consecuentes con los fines $y$ valores proclamados por la institución. Un acento fuerte en los fines obligaría a poner en un primer lugar, a la institución judicial y no como parece ocurrir en este diagnóstico, en las ventajas y los cálculos de oportunidad. A falta de un pensamiento institucional queda un espacio abierto para la reproducción de las prácticas viciadas en todos los escalones de la institución; a criterio de la funcionaria judicial ello se traduce en la pérdida de responsabilidad y mística entre la judicatura "rasa", lo cual ocurre de la mano de una creciente preocupación por la carrera, el ascenso y la ventaja personal. Dicho en otro lenguaje, las relaciones con la institución tienden a volverse utilitarias o funcionales, nada muy distinto de lo que se encuentra recurrentemente en las demás instituciones públicas en la Costa Rica del nuevo siglo.

Este último texto fue publicado en la prensa en enero del 2012; este recuerda una dimensión que pasó a un segundo plano en los sucesos de noviembre de ese mismo año. El Poder Judicial que parecía cerrar filas para defenderse de una agresión exterior, tenía fracturas y desgastes. Si el diagnóstico de los vicios estructurales tiene algún asidero, surge entonces una pregunta respecto a todo aquello que ha venido minando la legitimidad del Poder Judicial desde su interior, sin comprometer a disposición de la población para acudir a los tribunales, pero tal vez sí la confianza en una justicia pronta y efectiva.

La crítica de la jueza concluye con una invitación a cumplir con el oficio, al cual se deben quienes integran el Poder Judicial. Ella distingue entre la lealtad a los fines de la institución y la lealtad al cuerpo realmente existente, supone que la participación en la vida judicial delimita maneras más o menos coherentes y apropiadas de hacer las cosas, así como hay una distancia entre estas $y$ muchas de las prácticas existentes.

Una gran distancia separa esta crítica y la del diputado que pedía el alineamiento de la Sala Constitucional; entre ambas queda un gran espacio para muchas otras lecturas. Un rasgo notorio de muchas de ellas, cuando menos en lo que va del siglo xxi, es la sospecha recurrente de que las decisiones de la cúpula judicial y de la Sala Constitucional podía ser torcidas políticamente, algunas veces por intereses identificados con precisión. Este era uno de los temas que pasaron a primer plano, en el proceso de reelección del magistrado Cruz, el de la cuestión de la autonomía y la independencia.

En el año 2003, el cambio de criterio en cuanto a la reelección presidencial estuvo rodeado por fuertes señales de injerencia política. Al resolver sobre la reelección, la Sala Constitucional despejó el camino libre para el regreso a la presidencia de Oscar Arias y para introducir, por una vía colateral, las reformas orientadas hacia la privatización y el mercado abierto todavía no conseguidas, algunas debido a las resoluciones anteriores de la misma Sala Constitucional. Gracias a una nueva composición del Tribunal Constitucional se impuso una polémica interpretación de la Constitución Política. Acaeció un alineamiento de la Sala con intereses particulares, políticos y económicos, en aras de romper el estado de estancamiento estructural-institucional diagnosticado a comienzos del nuevo siglo. Las resistencias jurídicas cedieron por el lado de la Sala Constitucional; el resto vino posteriormente. 
Despejado el asunto de la reelección, se allanó el camino para quienes decían luchar a favor del primer país desarrollado de América Latina, la ruta que llevó a la firma del TLc y a los sucesos del 2007-2008. En los años siguientes, los cables sobre Costa Rica liberados por Wikileaks apuntalaron la evidencia existente de contactos formales e informales entre la Embajada Estadounidense y el Gobierno, así como entre este y la Sala Constitucional durante toda la tramitación del TLc, contactos lo suficientemente intensos para poder anticipar cómo y cuándo votaría el Tribunal Constitucional (Segnini, 02/03/2011: 6A). Los cables confirmaron las denuncias realizadas en la Asamblea Legislativa de un tráfico fluido entre la Sala Constitucional y la Presidencia de la República, de todo aquello que en el debate interno había ingresado antes con el curioso nombre de un "gemeleo de la Sala Constitucional".

El TLc trajo consigo un cambio sustancial en toda la organización política del Estado costarricense y una significativa transformación de la unidad jurídica nacional, al someter al Estado costarricense a decisiones que no provienen de sus propios tribunales. Le dio vía libre a un orden que pone los derechos patrimoniales de agentes externos e internos sobre los derechos fundamentales de las y los habitantes.

Pese a los repetidos señalamientos sobre lesiones a la Constitución y a la indicación expresa de lo que significaba para el sistema judicial nacional, fue aprobado con el voto de una mayoría de la Sala Constitucional y quienes podían poner límites en nombre de la Constitución y del proyecto de sociedad que ella condensaba, no lo hicieron (Asamblea Legislativa, 2007). Se está en el pico de un alineamiento entre el Poder Ejecutivo, la Asamblea Legislativa y la Sala Constitucional ${ }^{27}$ (Chacón, 27/05/2009) y por lo tanto, también en el punto ciego o zona gris presente en las palabras del magistrado Luis Paulino Mora ante la Corte,

$27 \quad$ Más tarde, ocurrió la resolución del recurso de inconstitucionalidad presentada por el diputado Sánchez para evitar su sanción, el cual, pese a serle desfavorable, generó sospechas sobre una posible relación entre la lentitud de la respuesta del Tribunal Constitucional y las calidades político-personales del implicado. el 19 de noviembre. Una parte sustancial de la quiebra del pacto social que él lamentaba se debía justamente a las políticas sociales y económicas puestas en marcha en las décadas anteriores, contra algunas de las cuales se resistió la Sala Constitucional, pero que con el TLC recibían la venia de la mayoría de integrantes de la Corte Constitucional, sin que ninguna voz fuerte saliera del Poder Judicial para denunciar un gran alineamiento de los tres Poderes, la con-fusión luego resentida. Dicho de una manera todavía más drástica, se está ante la razón por la cual quienes hablan de intereses fácticos no pueden darle un perfil concreto a los mismos y quizás también, ante el hecho simple de que una parte de nuestro sistema judicial esté articulado o integrado a esas fuerzas tan imprecisamente mencionadas.

Esta esquina de la historia invita a reflexionar sobre la co-responsabilidad de la Sala Constitucional en la conformación del cuadro social y político en el cual tuvo lugar, el intento de rechazar la reelección del magistrado Cruz, una de las voces que desde una posición de minoría trataron de ponerle un límite a los alcances del TLc desde la perspectiva constitucional. Fue el tribunal Contencioso-Administrativo que se pronunció sobre Crucitas e Industrias Infinito, el cual le puso una raya de no paso al Tribunal Constitucional y por esa vía, a quienes en nombre de la desregulación y los trámites expeditos, así como, la seguridad jurídica, corrieron la baranda de las leyes ambientales según conveniencia.

Lo acaecido en el trámite de aprobación del rLc, las fracturas y las facturas políticas incluidas, revirtieron en los procesos de elección y reelección de las magistraturas. Fueron la causa inmediata de un intenso debate en la Asamblea Legislativa en el año 2009, cuando se decidió la reelección de la magistrada constitucional Ana Virginia Calzada, presidenta del Tribunal durante la discusión del rLc; quienes se le opusieron, propusieron la necesidad urgente de renovar ese tribunal en su totalidad; en esta ocasión, la Sala Cuarta fue calificada desde la oposición legislativa como una instancia eminentemente política y en una "especie de Senado", al punto de barajar la idea de una 
limitación del período de nombramiento $y$ de las posibilidades de reelección de las y los magistrados (Vizcaino, 26/02/2009). Si se observa la terminología empleada, resaltan algunas semejanzas con la utilizada por los contrarios a la reelección en el 2012, solo que esta vez el reproche no apuntaba a la falta de alineamiento, sino por el contrario, a su exceso. En esa misma ocasión, diputados socialcristianos favorables a la reelección de la magistrada, alegaron que los excesos y el intervencionismo de la Sala Constitucional eran imputables a la Asamblea Legislativa y no a esta. De ese lado de la línea, aparecía entonces Francisco Antonio Pacheco, la persona que presidió la Comisión de Notables, entonces presidente de la Asamblea Legislativa.

El problema de la independencia aparecerá dentro de la institución judicial vinculado al sistema de reglas internas de administración y selección de jueces, a la discusión sobre la autonomía real de los jueces y juezas respecto a la Corte Plena $y$ al debate sobre quién encarna realmente el Poder Judicial. El problema se ha presentado con distintas facetas desde el año 2000 en adelante, oscilando entre las denuncias de presiones directas e indirectas sobre los jueces y juezas, hasta el delicado tema de las magistraturas suplentes.

Desde los primeros años del nuevo siglo, se encuentran fricciones de intensidad desigual y motivos distintos entre la Corte y la Fiscalía General de la República, en los cuales vuelve el tema de la independencia política. Cuando la causa contra el ex presidente Calderón Fournier llegó a la Sala Tercera para su revisión, trascendió la noticia de contactos entre algunos magistrados $y$ magistradas $y$ personas directamente interesadas en el resultado del juicio. El Fiscal General ordenó una indagatoria y por ello fue puesto en la picota por las y los implicados; el supuesto error del Fiscal General fue intervenir en una situación en la cual estaban implicados un grupo de magistrados y magistradas. Al mismo tiempo, los ex presidentes condenados en primera instancia, denunciaban que los suyos habían sido juicios políticos sin relación alguna con la justicia y ponían en tela de duda que hubiesen recibido un trato conforme al Estado de Derecho. Los ex presidentes enjuiciados reclamaron una justicia arbitraria - ni pronta ni cumplida - y se quejaron de un complot dirigido desde la Fiscalía General de la República (Bejarano, 2012). Sus versiones de los hechos son un ataque frontal al sistema de justicia, aunque los indicios son que sus alegatos tuvieron consecuencias; la Sala III descalificó una parte sustancial de la prueba condenatoria aportada por la Fiscalía, lo cual tuvo implicaciones en la condena de uno de los acusados y repercutió en la absolución del otro.

Nuevamente, la figura del Fiscal General estuvo en un primer plano a propósito de los sucesos relacionados con los dineros del Banco Centroamericano de Integración Económica, en el cual el principal implicado era el ministro de la Presidencia Rodrigo Arias. Hubo llamadas $y$ acusaciones de tráfico de influencias. Otra vez en este caso, surgieron sospechas de que la independencia de los poderes había quedado comprometida, ahora en beneficio del ex ministro.

Situaciones como estas ponen ante una línea delgada y sumamente móvil de choques en los cuales la autonomía del Poder Judicial ( $y$ en él) viene quedando recurrentemente en tela de duda. Una y otra vez se repiten términos y cargos semejantes, desde posiciones políticas distintas. De manera ascendente, la cuestión de la independencia del Poder Judicial ocupa a principios del nuevo siglo, una posición que recuerda la discusión nacional sobre la independencia de las autoridades electorales a mediados del siglo pasado. De ser así y todo sigue igual, los augurios no son buenos.

Quinto: Se llega a una situación con dos puntas políticas. Una lleva a la manera que pueden jugar las tensiones y contradicciones presentes en el Poder Judicial para favorecer o impedir, cambios en nombre de una $u$ otra reforma de actualización institucional considerada urgente. Este extremo conduce a los debates internos, a las diferencias personales, políticas e ideológicas, $y$ a las posiciones que ganan o pierden fuerza en el contexto de la manera como se transforma el país. Para un observador ajeno a la institución, seguir y entender lo que ocurre a este nivel no es fácil; siempre se tropieza con una capa de hermetismo y con códigos difíciles 
de descifrar. La discreción propia de todo Poder Judicial en razón de sus tareas, se recubre adicionalmente con brumas que ocultan luchas $y$ manejos políticos, internos y externos. Comparada con el Poder Judicial, decía la candidata a una de las magistraturas en la Comisión de Nombramientos, que la Asamblea Legislativa tiene la transparencia de una pecera.

La otra punta política lleva a la renovada importancia de los procesos de elección y reelección de las y los integrantes de la magistratura. En el 2003, se aprendió (o se actualizó) una importante lección: el giro del Tribunal Constitucional respecto a la reelección presidencial estuvo precedido por la sustitución de dos magistrados titulares. Otros hechos con resonancia pública, mostrarán la importancia de tener a las personas adecuadas en el lugar adecuado. Uno fue el caso del magistrado suplente de la Sala Constitucional, Federico Sosto, quien en el 2008 participó en varias resoluciones sobre la agenda de implementación del TLc, mientras fungía como asesor de la Casa Presidencial. Sosto asesoró a la presidencia de la República en la controversia sobre los dineros provenientes del Banco Centroamericano de Integración Económica, en el cual el principal implicado era el ex vicepresidente Rodrigo Arias Sánchez. En votación secreta, la Corte acordó en una votación de diez a favor y doce en contra, desestimar un proceso contra el magistrado. A criterio del Presidente de la Corte, Sosto no había faltado a la ley y su actuar no comprometía la reputación de la Sala Constitucional (Murillo, 24/07/2008). Pese a ello, la presión fue lo suficientemente importante como para que el magistrado suplente se viese obligado a presentar su renuncia; se está en la fase "flexible" de designación de las magistraturas suplentes.

Otro caso parecido fue el del políticomagistrado suplente de la Sala Primera, Moisés Fachler, en el año 2011, señalado de filtrar el borrador de una sentencia de la Sala Primera a la minera Industrias Infinito. Este alineamiento-coordinación resultó de convergencias anteriores. Los jueces del Contencioso Administrativo que valoraron los permisos del proyecto hablaron de una concertación de voluntades para aprobar la concesión; sin embargo, un pronunciamiento de mayoría de la Sala Constitucional había legitimado lo actuado. Para los defensores de la inversión minera, todo el proceso habría transcurrido conforme a la legalidad y la Constitución; algunos de ellos, que desde antes han llamado a redefinir las atribuciones de la Sala Constitucional, se pusieron del lado del Tribunal Constitucional, al punto de augurarle su muerte si no se imponía sobre la resolución del Contencioso, refrendado después por la Sala Primera. La persona que hizo estas advertencias, fue magistrada suplente a finales del siglo anterior $y$ entonces tuvo que renunciar por intervenir en la tramitación de un caso interpuesto por su propio bufete; estos antecedentes se desdibujaron cuando se convirtió en uno de los principales arquitectos de la reelección presidencial $y$ luego en defensor del TLC $y$ en abogado de los intereses mineros. En el intermedio queda la situación que se presentó en la Sala Tercera cuando corrió la noticia de los contactos telefónicos entre personas interesadas en el juicio del ex presidente Calderón Fournier $y$ algunos de las y los magistrados que debían resolver la apelación elevada. El entonces presidente de la Sala Tercera, magistrado Arroyo Gutiérrez, fue hostigado de manera anónima, bajo la presunción de que su voto sería desfavorable al ex presidente.

Situaciones como estas han revertido en los enfrentamientos entre la Corte y la Asamblea Legislativa a causa de la manera de selección de las personas que integran las listas entre las cuales, la Asamblea debía escoger a los magistrados suplentes. La pugna empezó a tomar forma a mediados del 2008; entonces un sector de la Corte reconoció fallas en la elección de magistrados suplentes, aunque otro con fuerza para imponerse, continuaba hablando del caso Sosto, de una situación artificial, creada por los medios y aupada por los resentimientos políticos generados por el TLc. Pocas personas apreciaron entonces la manera en la cual quedaba comprometida la credibilidad de la institución judicial. Incluso, el magistrado suplente implicado en el "affaire", defendió públicamente que la posición de bisagra entre dos poderes (la coordinación o la con-fusión) era lo propio de la magistratura en 
un Estado moderno 28 (Murillo, 10/07/2008: 5A). Esta tesis sobre el Estado moderno adelantaba la posición del diputado que pedía alineamiento, el cual, en ese tanto, no verbalizaba una ocurrencia personal. No obstante, para que algo así suscitara indignación, tenía todavía que correr más agua por el río. Nuevamente, en agosto de 2011, se abrió una indagatoria contra un magistrado suplente, esta vez de la Sala Segunda, por aparente uso de su función magisterial en la atención de un litigio privado a su cargo. Este caso concluyó con la renuncia del magistrado implicado.

Recién a principios de 2012, fuertemente presionada por la Asamblea Legislativa, la cual devolvió en dos ocasiones la lista para escoger a los y las suplentes de la Sala Tercera, la Corte aprobó un reglamento para seleccionar a quienes ingresarían en la lista de la cual debía escoger la Asamblea Legislativa la magistratura suplente. Mientras aparecía este nuevo filtro, los años de experiencia con el sistema de selección de las y los integrantes de la magistratura aportaban evidencia a favor de que el mecanismo era fundamentalmente político, revestido para aparentar una objetividad en la cual no se cree o se ha dejado de creer. Una molesta formalidad en los momentos decisivos, la cual se ha conservado $y$ practicado cual si funcionara adecuadamente, pese a que una $y$ otra vez su utilidad ha sido públicamente puesta en duda. Por encima de los atributos o las limitaciones de las y los postulantes, lo decisivo parece ser la confianza-afinidad que él o ella tenga o despierte en el bloque o partido que disponga los votos necesarios para su elección o los pueda reunir, lo cual se entrecruza en años recientes con los

$28 \quad$ Al respecto consultar el periódico La Nación, en su artículo "Magistrado Suplente de la Sala IV asesora la Casa Presidencial", 10/07/2008, p. 5A, la siguiente cita: "Consultado sobre la conveniencia de que un magistrado de la Sala IV tenga un nexo con el Ejecutivo, Sosto respondió: una relación totalmente alejada (entre ambos poderes) no es una concepción en el Estado moderno". En esta misma nota de prensa aparece la información de que Sosto compartía su oficina con el regidor libertario Jorge Alberto Hidalgo Vega, uno de los abogados contratados por la Casa Presidencial con los 2 millones de dólares donados por el Banco Centroamericano de Integración Económica. cálculos sobre la composición de los tribunales que recibirán los casos más delicados, en alzada.

Si algo diferencia esta situación respecto de la existente hasta finales del siglo pasado, cuando los magistrados y magistradas se escogían mediante acuerdos directos entre los dos partidos mayoritarios, no es porque se había llegado a introducir un filtro (más objetivo) de selección, como se creía inicialmente, sino en un grado muy importante, por la transformación morfológica de la Asamblea, por su fraccionamiento y las dificultades para conseguir acuerdos de manera expedita. Una situación que puede cambiar $y$ que no da ninguna seguridad. En el segundo quinquenio del nuevo siglo, la pulverización-atomización de la Asamblea había avanzado lo suficiente como para que se lograsen construir acuerdos centrados en intercambios de favores con algunas de esas micro fracciones.

Lo que sucede en la relación entre la Asamblea Legislativa y el Poder Judicial da cuenta de un patrón que debe observarse con mayor proximidad. Punto de partida $y$ resultado es una forma de ejercicio del poder que compromete la capacidad de aprendizaje $y$ de innovación.

El 27 de noviembre de 2012, los medios daban a conocer una declaración conjunta de diez puntos firmada por la Presidenta Chinchilla y los presidentes del Poder Legislativo y del Poder Judicial. Aparentemente, los responsables de los supremos Poderes coincidían en un texto en el cual manifestaban su preocupación por los hechos ocurridos en relación con la elección del magistrado Cruz, los cuales, según se lee en el escrito firmado, habían llevado a un enfrentamiento entre los Poderes Judicial y Legislativo (el Ejecutivo es dejado por fuera, cual si hubiese sido ajeno). Lo sucedido era puesto en relación directa con un deterioro de las relaciones entre los Poderes de la República, el cual comprometía su capacidad para reaccionar de manera rápida ante situaciones urgentes. En la declaración se reafirmaba nuevamente la independencia del Poder Judicial y al mismo tiempo se anunciaba que en una fecha próxima se darían a conocer las conclusiones de la comisión de expertos convocada por la Presidencia 
para revisar el marco institucional del Estado Costarricense $y$ fortalecer la gobernabilidad democrática. El escrito concluye con el compromiso de emprender un diálogo entre los tres poderes; la idea era reducir tensiones. Como suele ocurrir, en esta ocasión se volvió a repetir que Costa Rica tenía la democracia más sólida de América Latina y una de las más consolidadas del mundo. Con todo, seguíamos siendo un ejemplo excepcional (Informa-Tico, 27/11/2012.).

El encuentro de noviembre, para decirlo de una manera fuera de uso, adolecía de una falta de autenticidad. Una cosa es tratar de evitar que las aguas se sigan desbordando, otra querer cambiar el rumbo seguido y la forma de hacer las cosas. Nada sugería en aquel momento lo segundo.

Unos días después, el 3 de diciembre de 2012 , todavía con la controversia presente y con gente agitando el asunto de la ingobernabilidad, un diputado liberacionista felicitaba a sus colegas porque ese día, finalmente, había ocurrido la elección de la Subcontralora General de la República, otro de esos nombramientos con los cuales la Asamblea estaba en deuda con el país, según se suele decir. La nueva Subcontralora resultó electa con veintiocho votos. El Partido Liberación Nacional (PLN) la respaldó en bloque $y$ sus diputados $y$ diputadas hablaron de la persona electa de la mejor manera.

El mismo día del nombramiento, inmediatamente después de la votación, un diputado preguntó a la presidencia de la Asamblea si la recién electa cumplía con los requisitos mínimos para el puesto y si ella aceptaba el cargo; las dos cosas eran ignoradas después de la votación. La persona escogida no había presentado sus atestados ante la Comisión de Nombramientos, ni participó en el concurso convocado para llenar el puesto. Su nombre emergió en el momento mismo de la elección ${ }^{29}$ (ASPAL, nro. 107, 03/12/2012: 11-16). En su respuesta, el presidente de la Asamblea dijo no conocer a la nueva Subcontralora y se limitó a mencionar los requisitos cuyo

$29 \quad$ Intervenciones de los diputados Luis Gerardo Villanueva Monge y José María Villalta FlórezEstrada. cumplimiento se debían verificar ${ }^{30}$ (ASPAL, nro. 107: 11-12).

La elección de la Subcontralora fue legal pero sin transparencia $y$ en detrimento del mecanismo previsto (instituido) para una selección más objetiva o menos política de quienes se postulan para puestos públicos de decisión legislativa ${ }^{31}$ (Acta de la Sesión Ordinaria 33, 09/04/2012: 3-9). Un acto jurídicamente legítimo pero que no generaba confianza, dos cosas importantes de diferenciar. Para quienes votaron por la Subcontralora, un criterio decisivo parece haber sido sus vínculos con el pLN y la activa participación de la recién nombrada en las resoluciones sobre el tLc y su agenda de implementación, en su condición de asistenta del director de la Asamblea Legislativa. La recién electa trabajó entonces muy de cerca de la persona que coordinó después la Comisión de los Notables, entonces presidente de la Asamblea Legislativa. Un criterio importante y posiblemente válido; sin embargo, no fue expuesto con antelación, porque no hubo una presentación de la candidata y se desconocían sus méritos. Otra vez en esta oportunidad, las razones aparecieron después de la elección ${ }^{32}$ (ASPAL, nro. 107: 21-22). Nuevamente, dos personas con permiso tomaron parte en la elección para hacer mayoría; aparentemente, una era la diputada enferma llevada para completar los treinta y ocho votos en la elección de Cruz.

30 Intervención del diputado presidente Víctor Emilio Granados Calvo.

31 En mayo de 2012, ocurrió la elección de la Contralora General de la República. La persona que salió electa no se presentó para este puesto sino para el ocupar la Subcontraloría, puesto en el que se venía desempeñando desde el año 2004. Cuando concluyó su trabajo en el mes de abril, la Comisión de Nombramientos entrevistó y calificó 18 personas. El nombre de la futura contralora no aparecía en esa lista, porque según lo manifestó, "ni siquiera se lo había planteado". Su opción había sido siempre la Subcontraloría y en consecuencia, aparecía en la lista de dieciocho personas postulantes para el puesto. Quien luego resultó electa no estaba ni entre los postulantes ni entre los finalistas recomendados. Comisión Permanente Especial de Nombramientos.

32 Intervención del diputado Juan Carlos Mendoza García. 


\section{BIBLIOGRAFÍA}

Acta de la Sesión extraordinaria de Corte Plena nro. 40-12. 19/11/2012.

Acta de la Sesión Ordinaria, nro 33. 9/4/2012.

Acta de la Sesión Plenaria de la Asamblea Legislativa (aspaL), nro. 41-2012. $26 / 12 / 2012$

Acta de la Sesión Plenaria de la Asamblea Legislativa (ASPAL), nro. 54. 16/08/2004.

Acta de la Sesión Plenaria de la Asamblea Legislativa (ASPAL), nro. 68. 20/9/2012.

Acta de la Sesión Plenaria de la Asamblea Legislativa (ASPAL), nro. 99. 15/11/2012.

Acta de la Sesión Plenaria de la Asamblea Legislativa (ASPAL), nro. 100. 19/11/2012.

Acta de la Sesión Plenaria de la Asamblea Legislativa (ASPAL), nro .101. 20/11/2012.

Acta de la Sesión Plenaria de la Asamblea Legislativa (ASPAL), nro. 102. 21/11/2012.

Acta de la Sesión Plenaria de la Asamblea Legislativa (ASPAL), nro. 107. 3/12/2012.

Alfaro-Redondo, Ronald y Seligson, Mitchell. Cultura política de la democracia en Costa Rica, 2012: La erosión de los pilares de la estabilidad politica (Versión abreviada). San José, Costa Rica: Estado de la Nación-Universidad de Costa Rica-Barómetro de las Amércas-Latin American Public Opinion Project (LAPOP)Centro Centroamericano de Población (ccP), 2012.

Alfaro-Redondo, Ronald. "Evolución de la confianza en las instituciones en Costa Rica, 2004-2012". Cultura política de la democracia en Costa Rica. Mitchell A. Seligson (ed). 2012: 30

Alfaro, Ronald y Seligson Mitchell. "Cultura política de la democracia en Costa Rica, 2012". La erosión de los pilares de la estabilidad política (versión abreviada). Estado de la Nación-Universidad de Costa Rica-Barómetro de las Américas-LAPOP-CCP, 2012: 30

Arias, Oscar. Hagamos juntos el camino. Discursos, artículos, ensayos. San José, Costa Rica: Partido Liberación, Instituto Rodrigo Facio, 2005.

Asamblea Legislativa. Comisión Permanente Especial de Relaciones Internacionales y Comercio Exterior. Tratado de Libre Comercio República DominicanaCentroamérica-Estados Unidos. Dictamen negativo de minoría suscrito por la diputada Elizabeth Fonseca Corrales, Francisco Molina Gamboa y Ronald Solis Bolaños. 10/01/2007. Banco Interamericano de Desarrollo. Modernización del Estado $y$ Fortalecimiento de la Sociedad civil. Departamento de Planificación Estratégica y Políticas Operativas. Washington dc, 1990: 2.

Bejarano, Gloria. Sin derecho a la ley. San José, 2012.

Casas Zamora, Kevin. "Réquiem por un sueño". La Nación. 10/1/2012: 29 A.

Casas Zamora, Kevin. "Violencia, inseguridad ciudadana $y$ desarrollo humano en Costa Rica. Una aproximación conceptual y democrática". Memoria del Taller de Respuestas democráticas al problema de la violencia. San José. Fundación para la Paz $y$ la Democracia (funPadem), octubre 2004.

Chacón, Vinicio. "El caso del diputado Sánchez quedó impune". Semanario Universidad. 27/5/2009: 8-9.

Chinchilla, Laura. "Oportunidad para nuestra democracia”. La Nación. 18/01/2013: 31A.

Chinchilla, Rosaura. "Legitimación democrática e independencia judicial en cR". Extra (Página Abierta). 31/01/2012: 2-3.

Comisión Permanente Especial de Nombramientos. "Reeleción o no del magistrado Fernando Cruz Castro, como magistrado de la Sala Constitucional de la Corte Suprema de Justicia”. Informe afirmativo de mayoría. Expediente 18.583. 8/10/2012.

Delgado, David. "Magistrado alegó represalias de diputados para pedir alza salarial". $L a$ Nación. 19/3/2012:16 A.

Diario Extra. "Arranca elección al magistrado de la Sala Iv". Diario Extra. 22/11/2010: 8.

Flórez-Estrada, María y Hernández, Gerardo (editores). TLC con Estados Unidos. Contribuciones para el debate. San José: Instituto de Investigaciones Sociales de la Universidad de Costa Rica, 2004. 
Hernández, Rubén. "¿Quién gobierna en Costa Rica?”. La Nación. 17/3/2009.

Informa-Tico. "El sistema urge reformas: presidentes de supremos poderes". Informa-Tico. 27/11/2012. En: < http:// www.informa-tico.com/27-11-2012/ sistema-urge-reformas-presidentessupremos-poderes>

Kevin Casas y Fernando Sánchez. Memorándum. Algunas acciones urgentes para activar la campaña del Sí. 29/07/2007. En: <http://es.scribd.com/ doc/3954620/Memorando-del-miedo>.

Lora, Eduardo (editor). El estado de las reformas de estado en América Latina. Bogotá, Colombia: Mayol Ediciones, 2007.

Mata, Esteban. "Hay persecución política por lo que uno expresa". Entrevista a Ernesto Jinesta Lobo. La Nación. 19/09/2010: 6A.

Miranda, Hulda. "Plan de sobresueldo llegó a la Corte "por error", según magistrados". La Nación. 14/03/2012: 15 A.

Mora, Luis Paulino. "El malestar con la justicia”. La Nación. 20/5/2012: 29 A.

Murillo, Álvaro. "Nuevo magistrado de Sala Iv: las ideologías estupidizan a la gente". La Nación. 26/06/2011: 6 A.

Murillo, Álvaro. "Magistrado Suplente de la Sala Iv asesora la Casa Presidencial". La Nación. 10/07/2008: 5A.

Murillo, Álvaro. "Presidente de la Corte. 'No soy un juez ético sino de legalidad". La Nación. 24/07/2008. En: <http:// wvw.nacion.com/ln_ee/2008/julio/24/ pais1632377.html>

North, Douglas. Instituciones, cambio institucional y desempeño económico. México. Fondo de Cultura de Cultura Económica, 1993.

Ordóñez, J. (Dir. de proyecto). Primer Informe Centroamericano de Gobernabilidad Jurídico-Institucional 2007-2008. Guatemala de la Asunción-San Salvador-Tegucigalpa-Managua-San José: Observatorio de la Democracia en Centroamérica-Instituto Centroamericano de Gobernabilidad, 2010.

Pacheco, Francisco (Coordinador). Informe final Comisión Presidencial sobre
Gobernabilidad Democrática. Propuestas para fortalecer la funcionalidad $y$ calidad de la democracia costarricense. Mideplan, 2013. En: <http://www.conare. ac.cr/proyectos/Informe+notables + final2.pdf $>$.

Poder Judicial. Encuesta para medir el índice de confianza judicial en la sociedad costarricense. Enero 2012. En: <www. poderjudicial.go.cr>

Prats i Catalá, Joan. "Gobernabilidad democrática para el desarrollo humano. Marco conceptual y analítico". Revista Instituciones y Desarrollo 10. Instituto Internacional de Gobernabilidad de Catalunya, Barcelona. 2001: 103-148.

Programa de Naciones Unidas para el Desarrollo-pnud. "Venciendo el temor. (In) seguridad ciudadana y desarrollo humano en Costa Rica". Informe Nacional de Desarrollo Humano 2005. San José, Costa Rica: pnud, 2006.

Méndez, William. "pusc ataca el discurso de Figueres”. La Nación. 03/05/1995. En: <http://wvw.nacion.com/ln_ee/1995/ mayo/03/pagina04.html>.

Ramírez, Ernesto. "Ana Virginia Calzada, presidenta de la Sala Constitucional: a la Sala le delegan los problemas que debe resolver el Ejecutivo y el Legislativo". Semanario Universidad. 30/05/2012: 7 .

Rivera, Ernesto. "PLn aprovechará jubilación de magistrados para cambiar rostro a la Corte". Seminario Universidad. 03/04/2013. En <http://www.semanariouniversidad. ucr.cr/component/ content/article/2057$\mathrm{Pa} \% \mathrm{C} 3 \%$ ADs/9370-pln-aprovecharajubilacion-de-magistrados-para-cambiarrostro-a-la-corte-.html>.

Rodríguez, Miguel Ángel. Dí la cara. Una batalla por el Estado de Derecho. Bogotá: Editorial Planeta, 2006.

Segnini, Giannina. "eeuu: Gobierno de Arias supo cómo votaría Sala iv sobre el tLc”. $L a$ Nación. 02/03/2011: 6A.

Sequeira, Aarón. "PAC pretende cambio extremo en magistrados constitucionales". La Prensa Libre. 26/02/2009. 
Solís, Manuel. La institucionalidad ajena. San José. San José, Costa Rica: Editorial de la Universidad de Costa Rica, 2006.

Universidad de Costa Rica. Roces constitucionales del Tratado de Libre Comercio entre República Dominicana, Centroamérica y Estados Unidos. En: $<$ http://iij.ucr.ac.cr/sites/default/files/ documentos/roces_constitucionales_ del_tlc_entre_republica_dominicana_ centroamerica_y_estados_unidos.pdf $>$.

Villalobos, Carlos. "Chinchilla llama a la Sala Iv 'cámara alta' que aletarga avance de leyes”. La Nación. 15/04/2012: 6A.

Vizcaino, Irene. "Diputados del pac niegan apoyo a magistrada por fallos de Sala Iv". La Nación. 26/02/2009: 7.
Wilson, Bruce; Rodríguez, Juan Carlos y Handberg, Roger. "A mayores previsiones... resultados imprevistos: Reforma Judicial en América Latinaindicios sobre Costa Rica". América Latina Hoy 39. 2005: 102-103.

Zúñiga, Roy y Vega, Rolando. Sistema de gestión integral para la justicia: calidad al servicio del ciudadano. San José, Costa Rica: Poder Judicial. En: <http:// www.poder-judicial.go.cr/Gica/edocman/ publicaciones/Articulo_Revista_No7_ Sala_Segunda.pdf $>$.

Fecha de ingreso: 11/07/2013

Fecha de aprobación: 30/10/2013 